\title{
High Temperature Tribology under Linear Oscillation Motion
}

\author{
Raj Shah ${ }^{1, *}$ (D), Rui Chen ${ }^{2, *}$, Mathias Woydt ${ }^{3}$, Christoph Baumann ${ }^{4}$, Joshua Jurs ${ }^{5}$ and Philip Iaccarino ${ }^{2}$ \\ 1 Koehler Instrument Company, Inc., 85 Corporate Drive, Holtsville, NY 11742, USA \\ 2 Department of Materials Science and Chemical Engineering, Stony Brook University, \\ Stony Brook, NY 11794, USA; philip.iaccarino@stonybrook.edu \\ 3 MATRILUB, D-12203 Berlin, Germany; m.woydt@matrilub.de \\ 4 Optimol Instruments Prüftechni k GmbH, Flößergasse 3, D-81369 München, Germany; \\ christoph.baumann@optimol-instruments.de \\ 5 Vanderbilt Chemicals, LLC, 30 Winfield Street, Norwalk, CT 06855, USA; jjurs@vanderbiltchemicals.com \\ * Correspondence: rshah@koehlerinstrument.com (R.S.); rui.chen.2@stonybrook.edu (R.C.)
}

check for updates

Citation: Shah, R.; Chen, R.; Woydt, M.; Baumann, C.; Jurs, J.; Iaccarino, P. High Temperature Tribology under Linear Oscillation Motion. Lubricants 2021, 9, 5. https://doi.org/10.3390/ lubricants 9010005

Received: 9 August 2020

Accepted: 20 October 2020

Published: 30 December 2020

Publisher's Note: MDPI stays neutral with regard to jurisdictional clai$\mathrm{ms}$ in published maps and institutional affiliations.

Copyright: $\odot 2020$ by the authors. Licensee MDPI, Basel, Switzerland. This article is an open access article distributed under the terms and conditions of the Creative Commons Attribution (CC BY) license (https:// creativecommons.org/licenses/by/ $4.0 /)$.

\begin{abstract}
High temperature tribology is considered to begin from a minimum temperature of 300-350 ${ }^{\circ} \mathrm{C}$, where organic base oils and polymers begin to decompose, until a temperature of $1000{ }^{\circ} \mathrm{C}$. In this field of tribology, tests are typically run under dry or solid-state friction, unless a solid lubricant is used, since most lubricants will oxidize or break down when exposed to these extreme temperatures. Therefore, this form of tribotesting is useful to determine the friction, wear, and other tribological characteristics of coatings, ceramics, alloys, cermets, and similar materials. Additionally, high temperature tribology is important to further understand the frictional interactions and adhesive behavior of contacts that operate at these high temperatures. When considering measurements of the tribological parameters in a high temperature application, the standard Schwingung, Reibung, Verschleiž (SRV) (Oscillating, friction, wear, in English) reciprocating, linear-oscillatory tribometer can be modified for testing temperatures of up to $1000{ }^{\circ} \mathrm{C}$ by using a high temperature heating block. With this configuration, the instrument can accurately monitor many parameters of the tribosystem, such as coefficient of friction, electrical resistance, zero stroke point, sliding speed, and others. As a result, the SRV instrument is shown to be a powerful tool for high temperature tribotesting. This paper will provide an overview of this high temperature tribology test rig and will discuss its versatility and efficacy, and will show how it can effectively be implemented in both research and practical applications for the development of various coatings and other high temperature tribological contacts.
\end{abstract}

Keywords: high temperature tribotesting; SRV; friction; wear; linear oscillation tribometer

\section{Introduction}

When exposed to high temperatures above $350-400{ }^{\circ} \mathrm{C}$, tribosystems must operate without liquid lubricants and a hydrodynamic film separating the mating surfaces. Some contacts in an internal combustion express an increase in wear, when exposed to unlubricated high temperature conditions [1], which is one of the engine's life limiting factors [2]. For example, in the tribosystem "valve seat/valve insert", hot combustion and oxygen-rich gases have been shown to accelerate exhaust valve failure in automotive engines, as a result of valve guttering and torching $[3,4]$. Similar dry friction and temperatures occur in waste gate valves and their bearings. Other applications where high temperature tribology analysis is useful are the metal processing of hot forging of steel and hot forming of metals parts, power generation, and aerospace industries. In the high temperature regime, tribosystems are exposed to static and tribologically enhanced oxidation, which impacts friction and wear resistance. Tribo-oxidation can be either detrimental or beneficial to wear at high temperatures in air.

In standard applications, lubricating oils and greases are used to provide improved frictional behavior and wear resistance and to help reduce corrosion. However, at high 
temperatures $\left(300-350^{\circ} \mathrm{C}\right)$ that are above the vapor pressure and / or decomposition temperature, base oils, additives, and polymers tend to decompose, rendering most of the lubricants useless. Fluid films accommodate the velocity difference between two surfaces, which under dry conditions proceed by another mechanism. Therefore, solid lubricants having lower vapor pressures and higher sublimation temperatures with lamellae structure are used. Solid lubricants demand high temperature stability, oxidation resistance, toughness, and hardness [5]. For high temperature applications, a tribocontact may consist of a ceramic, hard metal, cermet, or refractory metal alloy, either monolithically or as coatings for improved tribological properties, which form stable oxides with low shear strength [6].

In air, most metals are not stable, and will react with oxygen to form an oxide layer on the metal's surface $[7,8]$ as well as on non-oxide ceramics, cermets, and hardmetals. When exposed to high temperature, the oxidation behavior of the substrate can change, because they form different types of oxides. For example, iron and mild steels have been shown to form different types of oxides, depending on the temperature $[9,10]$. Below temperatures of $570{ }^{\circ} \mathrm{C}$, these steels will form $\mathrm{Fe}_{2} \mathrm{O}_{3}$ (hematite) and $\mathrm{Fe}_{3} \mathrm{O}_{4}$ (magnetite) oxides on the surface, which act as a protective layer or scale against further oxidation by increasing the diffusion resistance and adhesive wear (scuffing). Above this temperature, $\mathrm{FeO}$ forms, which increases the oxidation rate. On the surfaces of alloyed steels, high-temperature and hard facing alloys, chromium forms in air $\mathrm{Cr}_{2} \mathrm{O}_{3}$, nickel $\mathrm{NiO}$ or cobalt $\mathrm{Co}_{3} \mathrm{O}_{4}$ and mixed/double oxides $\left(\mathrm{FeCr}_{2} \mathrm{O}_{4}, \mathrm{NiCr}_{2} \mathrm{O}_{4}\right.$ or $\mathrm{NiFe}_{2} \mathrm{O}_{4}$.) are formed [11].

M.N. Gardos [12] coined the term "lubricious oxides" to describe expected low coefficients of friction (COF) and wear rates in unlubricated dry sliding conditions. The property-tribology relationship for tribo-oxidation is today related to sub-stoichiometric oxides. Sub-stoichiometric oxides formed by tribo-oxidation can have planar oxygen defects [6] such as $\gamma-\mathrm{Ti}_{3} \mathrm{O}_{5}, \mathrm{Ti}_{5} \mathrm{O}_{9}\left(\mathrm{Ti}_{\mathrm{n}} \mathrm{O}_{2 \mathrm{n}-1}, \mathrm{Ti}_{\mathrm{n}-2} \mathrm{Cr}_{2} \mathrm{O}_{2 \mathrm{n}-1}\right)$ and $\mathrm{Ti}_{9} \mathrm{O}_{17}$ and $\mathrm{Mo}_{0,975} \mathrm{Ti}_{0,025} \mathrm{O}_{2}$ as well as double oxides, such as $\beta-\mathrm{NiMoO}_{4}$ or $\mathrm{NiTiO}_{3}$, or the oxygen deficiency is accommodated by block-structures $\left(\mathrm{Nb}_{3 \mathrm{n}+1} \mathrm{O}_{8 \mathrm{n}-2}\right)$ [13].

High temperature tribological contacts can be quite complex and will influence the tribological properties. For example, thermal softening and annealing, phase transitions, oxidative morphological changes, diffusion, and surface degradation due to fatigue and wear [14]. To further the understanding of the high temperature contacts, reliable tribometers are needed to simulate the lubrication conditions of these contacts. This review will focus on one of these tribometers and will assess its capability to be used as an effective tool for research and development on high temperature tribological applications.

\section{Background}

The need to reduce dry wear effects has been around for thousands of years in simple tools and instruments. However, it was not until the industrial revolution that the uses of iron and steel shafts, along with softer bearing materials became more prominent [15]. In a study done by Professor D. Dowson [15], the wear effects of various material combinations were analyzed. The study focused on the friction effects of ceramic coatings, which were neglected in the times when steel and iron bearings were predominant, but have been gathering interest since they are less likely to react when compared to metal materials and their capabilities maintain their functions at elevated temperatures. The study shows that metal on metal combination gives the highest wear factor, $k$, while the ceramic on ceramic wear gives one of the lowest wear factors. Nevertheless, they are not impervious to wear and the aforementioned scenario only applies at moderate loads and speeds. An increase in the load, oscillation speed, or distance causes a decrease in wear resistance. Furthermore, the debris that result from the friction process can cause further wear damage due to their abrasive nature.

As medical technology advances, certain procedures such as total hip joint replacements (THRs) are made possible. However, the materials of the THRs will start to wear over time and a study by Beadling et al. [16] focuses on the tribological aspects of the metal-on-metal wear and degradation of THRs in order to reduce repeated revisions. In 
this study, the process of understanding the "tribocorrosive contact" was investigated using simplified 2D models and taking into account simple walking data. A simulator was used with three electrodes to measure the corrosive break down of the materials. The acquired result was that the tribological wear of the metal-on-metal materials greatly correlated with the electrochemical degradation. When the currents are at their highest, the lubricant films are at their thinnest, which leads to a cascade of increased abrasion and thus a higher corrosion. The authors admitted that while this study showed good results, it still has its limits in that more complicated tasks cannot be easily simulated. This work showed how tribology can be used for practical applications in the medical field.

\section{Tribometer for High Temperature Applications}

This review will focus on the Optimol Schwingung, Reibung, Verschleiž (SRV) tribometer, which is a widely used tribometer that can be modified for high temperature applications. The SRV exists in a variety of configurations, and it is most commonly used to simulate dry and lubricated contacts under linear, reciprocating motions. This tribometer uses an electromagnetic linear drive to generate periodic translational movement to an upper specimen, against a stationary lower specimen. Figure 1 visualizes this setup of the upper and lower specimen.

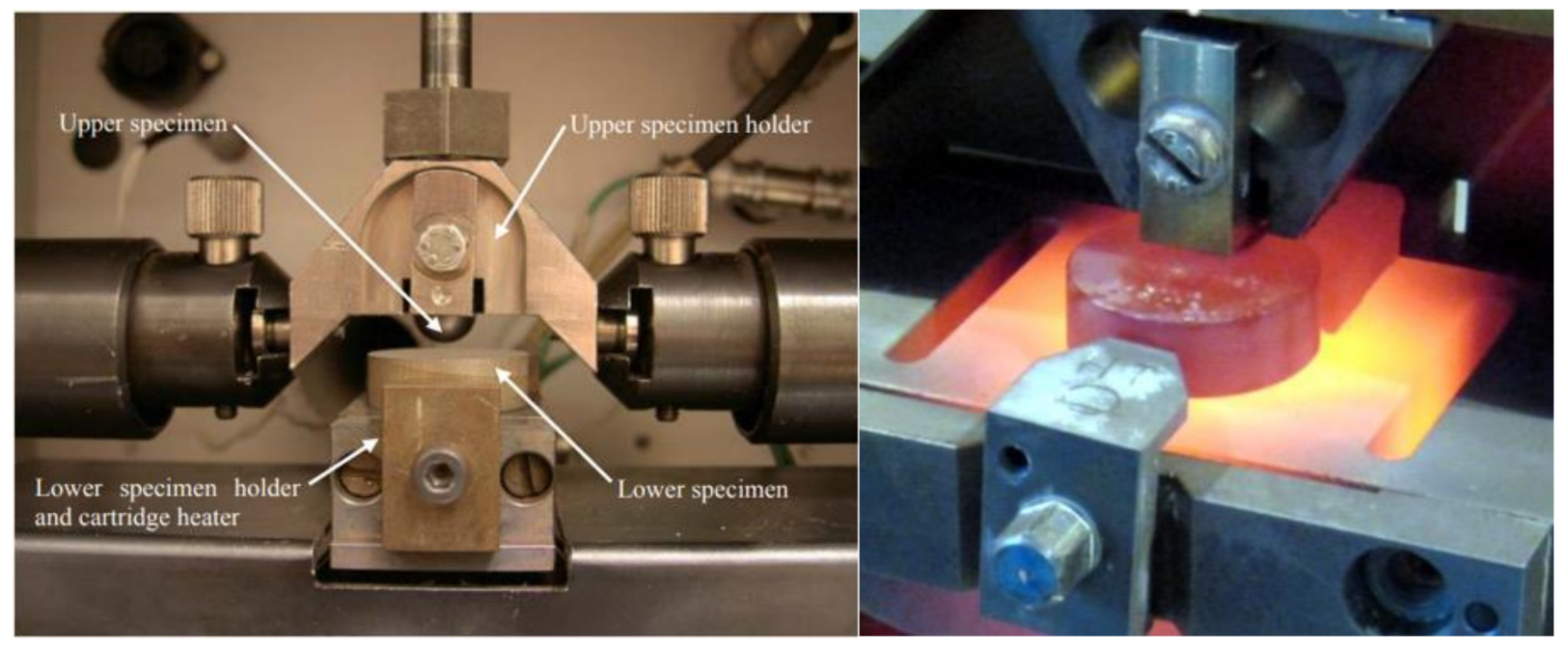

Figure 1. Test chamber of the Optimol Schwingung, Reibung, Verschleiž (SRV) reciprocating friction and wear tester.

To apply a normal force, a spring and servomotor apply a load on to the upper specimen, pressing it onto the lower specimen. As the upper specimen oscillates with a designated frequency and stroke length against the lower specimen, the tribological properties are monitored. The SRV can measure the frictional force, wear rates, contact resistance, and other characteristics of the tribosystem as a function of time throughout the test for up to a surface pressure of $5000 \mathrm{MPa}$. There are numerous ASTM, DIN, SAC, ISO and other standardized methods or tests that utilize the SRV instrument. In these tests the normal force is increased incrementally or stepwise over time to see how the tribological properties are affected. The ambient temperature is the key test parameter within high-temperature tribology.

The standard SRV model can be modified for high temperature applications through use of a heating block. For these applications, the standard block-which supports the lower specimen from below-is replaced with the high temperature heating block. The heating block is made of high temperature resistant materials, such as Inconel 600, and allows block temperatures to reach $1000{ }^{\circ} \mathrm{C}$. Optional is a vacuum-type system up to $1000{ }^{\circ} \mathrm{C}$ or a pressurized chamber for hot steam up to $750{ }^{\circ} \mathrm{C}$. Furthermore, the high temperature block is secured in place with adapters, clamps, and holders. This heating block permits the analysis of high temperature tribological contacts for research and 
development applications by monitoring and measuring a variety of properties, such as the coefficient of friction wear rate.

\section{Purpose and Methodology}

This paper aims to determine the efficacy of the SRV tribometer when examining the behavior of tribocontacts under dry friction and high temperatures. This will be accomplished by investigating and reviewing published literatures where this tribometer is used to evaluate the frictional and wear properties of a high-temperature tribosystem. These literatures will contain both research and practical applications. As SRV tribotesting is a wide and varied field, a few will be chosen and the important data on the main findings of the paper will be discussed in detail while others will have their results briefly summarized and discussed. Five of these published papers were chosen for a detailed review analysis: one paper regarding tribolayers, another about coatings, the third about an application of brake materials, the fourth on steel wear in automobiles, and the last on applications in drilling. Then, conclusions will be drawn, with regards to the SRV test rig's capability to be used in high temperature research and developmental applications in addition to real-world usage relevance.

\section{Experimental Comparisons}

\subsection{Tribolayers}

Tribolayers play a fundamental role in the dry wear of the metallic materials. However, most of the research studies done on the different subsurface zones are at room temperature. In a study done at the Ruhr-University Bochum, Institute for Materials, Bochum, Germany, the wear of the tribosystem nickel-based Alloy 80A — cast iron-was observed at high temperatures, with the use of an SRV tribometer, since mechanically mixed layers will develop at a rate much faster than when compared at ambient temperatures. In previous tests at room temperature, there are usually three subsurface layers. The mechanically mixed layer is the upper layer, which contains mixed materials from both the body and the counter body. The second layer, the middle layer, consists of ultra-fine structures that contain a composition that is typically the same as the base material. The third layer on the bottom does not contain any specific structures and instead contains deformed base materials. The experiments were performed at temperatures of $600{ }^{\circ} \mathrm{C}$ and $800{ }^{\circ} \mathrm{C}$, over a course of up to $10 \mathrm{~h}$. A tribometer with a hemispherical pin-on-disc configuration was used for this study, with the disc consisting of the cast iron and the pin consisting of the Ni-based Alloy 80A.

One section of the study focused on the sliding wear of the metals after $10 \mathrm{~s}$ of exposure, the results of which are shown in Figure 2. It can be clearly seen in the images that even after a brief contact of $10 \mathrm{~s}$ the materials of the pin are etched onto the disc. Figure 2a shows signs of wear and material deposit on the surface of the disc. Figure $2 b, c$ are taken with energy dispersive X-ray spectroscopy (EDX) and the bright parts indicate a high amount of $\mathrm{Ni}$ and $\mathrm{Fe}$, respectively. The high concentration deposit of $\mathrm{Ni}$ on the surface of the disc will change from dry friction wear of $\mathrm{Ni}$ on $\mathrm{Fe}$ to $\mathrm{Ni}$ on $\mathrm{Ni}$ if the test is to be continued. Using a focused ion beam (FIB) to cut out a portion of the disc, the Ni on the surface of the disc was observed to have ultra-fine-grained structures-which appears in zone 2 of the tribolayers present in a test done at ambient temperature. 

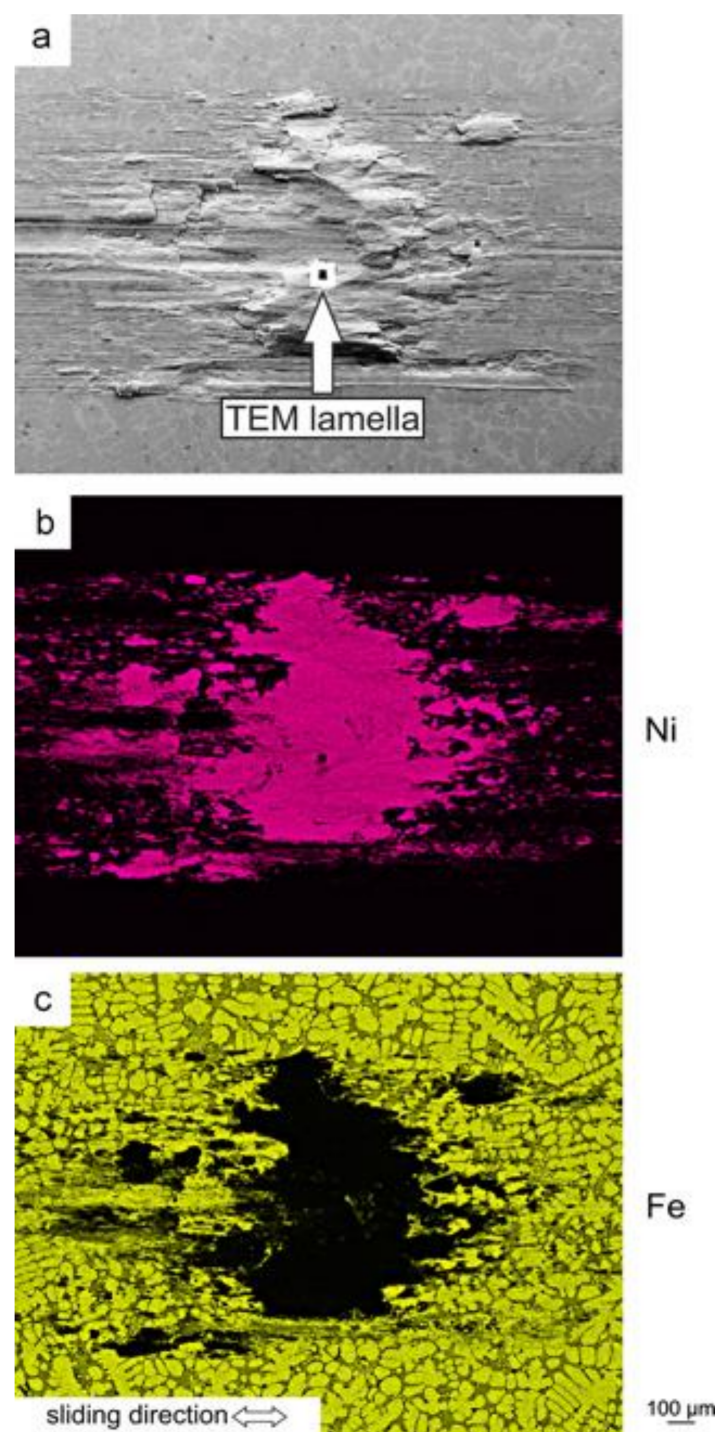

Figure 2. Image (a) results of cast iron disc after $10 \mathrm{~s}$ of exposure at $600^{\circ} \mathrm{C}$. Images $(\mathbf{b}, \mathbf{c})$ shows $\mathrm{Ni}$ and $\mathrm{Fe}$ in the highlighted areas, respectively [2].

The tests for $10 \mathrm{~h}$ for both $600{ }^{\circ} \mathrm{C}$ and $800{ }^{\circ} \mathrm{C}$ showed a much more pronounced wear and the surface patterns can be easily seen. Using a FIB, a portion of the Alloy 80A pin was removed and shown in Figure 3. Compared to the results at room temperature, tests done at both $600{ }^{\circ} \mathrm{C}$ and $800{ }^{\circ} \mathrm{C}$ show the formation of four subsurface zones. These tribolayers went through multiple iterations after a long period of wear exposure and the distinct layers formed as a result. Zone 1, the glaze layer (oxidized layer), has a very similar chemical composition compared to the Ni-based pin, with an increased amount of $\mathrm{O}$ and Fe. The development of this layer acts as a protective coating on the surfaces, assisting in reducing the wear rate of the objects. Zone 2 is very thin at $15 \mathrm{~nm}$ after exposure at $600{ }^{\circ} \mathrm{C}$ and $70 \mathrm{~nm}$ after exposure at $800^{\circ} \mathrm{C}$ and consists of $\mathrm{Cr}_{2} \mathrm{O}_{3}$. Zone 3 is the ultra-fine-grained layer and zone 4 is the plastically deformed layer without grain refinement that consists of the base material. Zones 1 and 2 in the disc have the same composition as those in the pin. Zone 3 is made up of material from the pin and zone 4 is the disc substrate. 


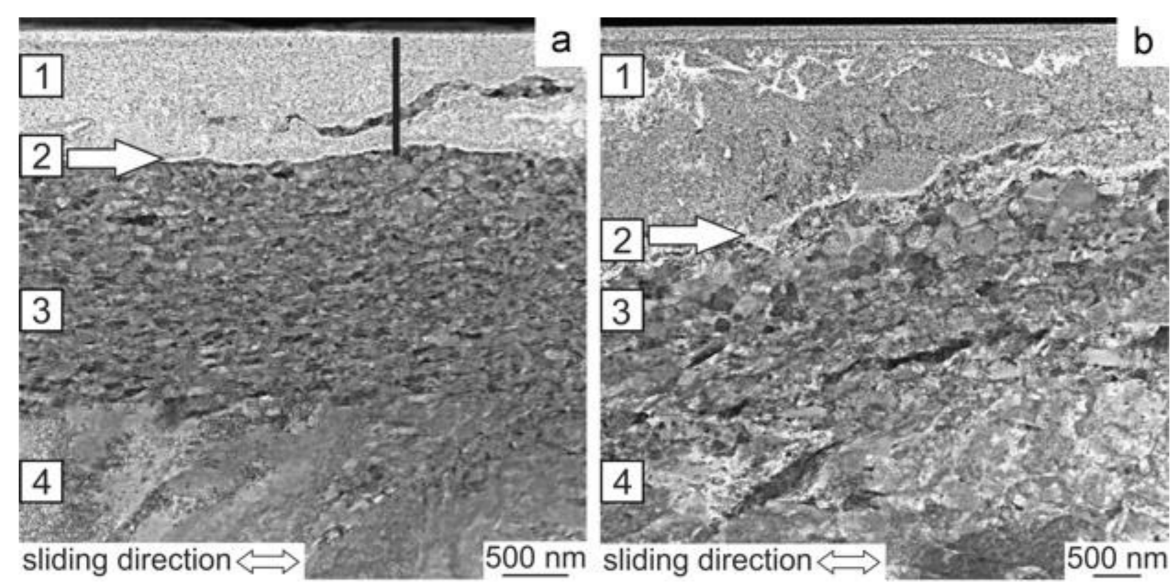

Figure 3. Cross sectional view near the surface of the pin after $10 \mathrm{~h}$ of exposure at both (a) $600{ }^{\circ} \mathrm{C}$ and (b) $800^{\circ} \mathrm{C}$ [2].

The process that the disc and pin went through during $10 \mathrm{~h}$ of wear is shown in Figure 4. After roughly 20 cycles, Ni metal starts to accumulate on the Fe disc and after 200 cycles the situation is the same as in Figure 3, where a lump of Ni accumulates on the surface of the disc. What follows after is the formation of the glaze layer through $\mathrm{Ni}$ on $\mathrm{Ni}$ contact and the repeating process of welding, fracturing, and re-welding the Ni particles, occurring after 10,000 cycles. After 720,000 cycles, which is after $10 \mathrm{~h}$ of wear exposure, the glaze layer covers a majority of the wear scars and an additional layer is formed. The $\mathrm{Cr}$ from the Ni-based pin and the $\mathrm{O}$ from the glaze layer react to form a layer of $\mathrm{Cr}_{2} \mathrm{O}_{3}$ directly underneath the glaze layer. The glaze layer exhibits a process that can be described as "self-healing" during wear exposure. When a piece is chipped off due to sliding friction, a piece of debris fills the gap that forms from the action. This occurs when steady state is reached, and the layers remain constant.

Overall, compared to the tests done at room temperature, the test at higher temperatures resulted in the formation of different tribolayers. In this study of dry sliding wear at temperatures of $600{ }^{\circ} \mathrm{C}$ and $800{ }^{\circ} \mathrm{C}$, the tribolayers "evolved" based on the conditions of both the disc and the pin throughout the experiment. Results at ambient temperature show that the three subsurface layers contain the expected mixture of materials of the two objects on the surface and only materials from the base object on lower levels. The high temperature testing shows a different result. The first layer, the glaze layer, proves to have a very beneficial effect as it seemingly heals itself and prevents damage on the inner levels of the materials, essentially minimizing the effect and rate of wear after a long period of exposure.

\subsection{Coating}

The use of coatings is a cost-effective alternative to designing superior materials to withstand the conditions of a high temperature tribosystem and to lessen the effects of wear due to extended exposure. For this reason, the paper "High temperature tribology of polymer derived ceramic composite coatings", which uses a steel ball-on-disc modulartribometer, by Sajid Ali Alvi and Farid Akhtar of Lulea University of Technology in Lulea, Sweden, was selected for review and discussion. As the name suggests, this specific study focuses on the reduction in frictional wear caused by the polymer derived ceramic (PDC) composite coatings. The authors opted for the use of solid lubricants formulated through the use of materials such as solid metals, fluorides, and metal oxides which are selected for their low vapor pressure at high temperatures and their ability to adapt to large temperature ranges. 


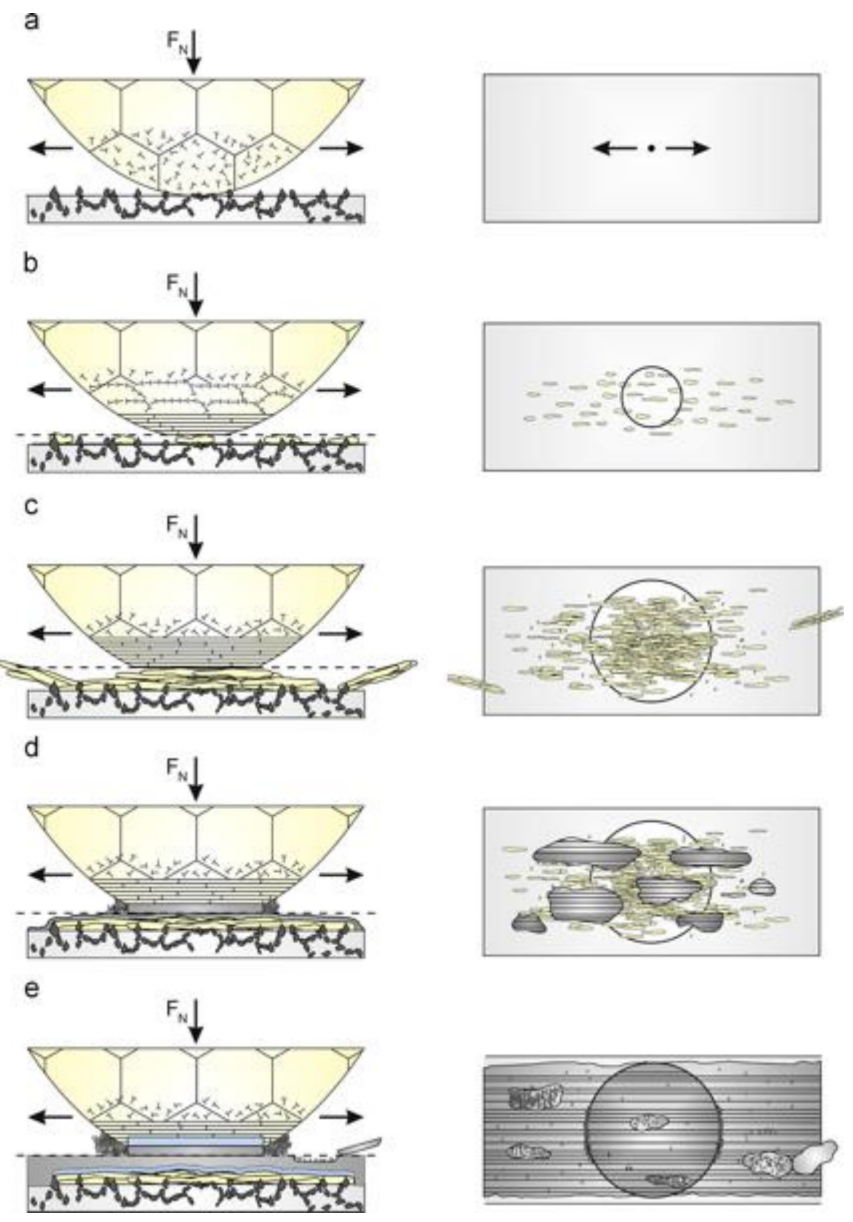

Figure 4. Schematics showing the change in wear after (a) 0 cycle, (b) 20 cycles, (c) 200 cycles, (d) 10,000 cycles, and (e) 720,000 cycles [2].

The focus of this paper is on the tribological properties of PDC at relatively high temperatures and loads. Although previous tests have been conducted, most, if not all, were done at low temperatures and low forces. Two PDC were studied and discussed in this research: $\mathrm{SiOC}-\mathrm{ZrSi}_{2}$ and $\mathrm{SiOC}-\mathrm{Ag}$, and the base substrate is AISI 304 stainless steel. Pure PDC, such as SiOC, have a maximum thickness of a few microns due to the shrinkage that occurs during the conversion from polymers to ceramics. One method of addressing this issue is the addition of fillers-either passive or active. Passive fillers can reduce the effects of the shrinkage while active fillers can form new phases through the interaction with gas products or with the atmosphere. For this reason, the active filler $\mathrm{ZrSi}_{2}$ and the passive filler Ag were chosen for the tribological tests.

The results from conducting various wear tests on the two coatings are shown in Figure 5. As the load increases, up to a max of 5 Newtons $(\mathrm{N})$, the coefficient of friction (COF) increases for $\mathrm{SiOC}_{-} \mathrm{ZrSi}_{2}$ but decreases for $\mathrm{SiOC}-\mathrm{Ag}$. Despite the increase in COF for $\mathrm{SiOC}-\mathrm{ZrSi}_{2}$ at higher forces, the COF is still lower than the value obtained for pure steel on steel contact at $1 \mathrm{~N}$. For tests at increasing temperatures, $\mathrm{SiOC}-\mathrm{ZrSi}_{2}$ shows high $\mathrm{COFs}$ for $150{ }^{\circ} \mathrm{C}$ and $300{ }^{\circ} \mathrm{C}$, but low values for $200{ }^{\circ} \mathrm{C}$ and $400{ }^{\circ} \mathrm{C}$. For SiOC-Ag, however, the $\mathrm{COF}$ seem to increase as the temperature increases. These results will be examined in more detail later on. 
(a)

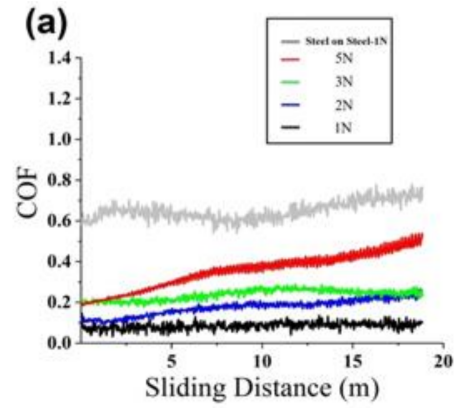

(c)

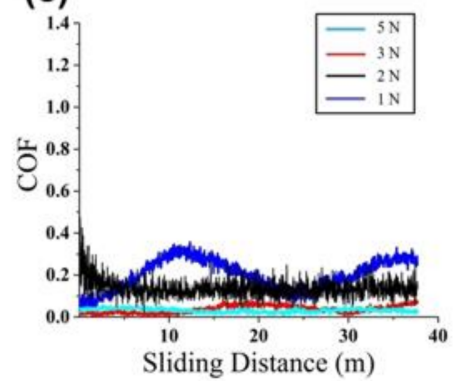

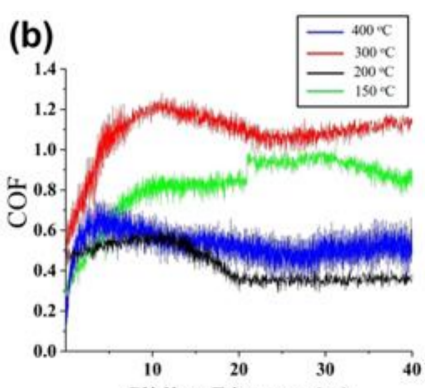

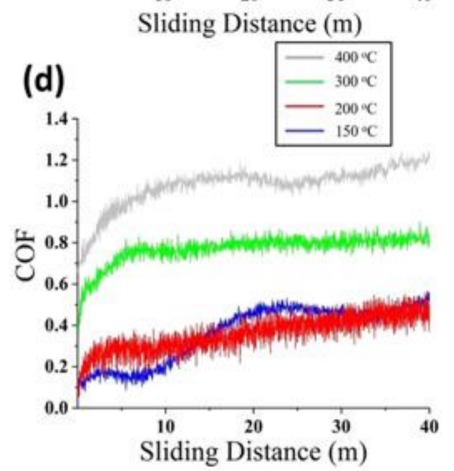

Figure 5. Friction coefficient curves of SiOC-ZrSi $2(\mathbf{a}, \mathbf{b})$ and $\mathrm{SiOC}-\mathrm{Ag}(\mathbf{c}, \mathbf{d})$ composite coatings under different temperatures and different forces [5].

The tests done on the two coatings at room temperature but with increasing loads are shown in Figures 6 and 7. Wear tracks for SiOC- $\mathrm{ZrSi}_{2}$ are very minor at low loads, with little amounts of base material present in the tracks. For the wear at $5 \mathrm{~N}$, the wear track was much more significant. Through these tests, the authors discovered that the coating has an adhesion of $6 \mathrm{~N}$, which is due to the reaction between the substrate and the polymeric precursor, polymethlysilsquioxane (PMS). The track wears on the SiOC-Ag coating were much less noticeable. As is shown in Figure 5, the COF for SiOC-Ag was much lower, which is a result of lubrication through coating transfer. As the wear progresses, the Ag in the coating "smears" onto the counter balls. An increase in the "smear" amount occurs when the load increases and this can be seen in Figure 7d, where a large amount of coatings were removed. Due to these differences, SiOC-Ag has a lower load bearing capability when compared with $\mathrm{SiOC}-\mathrm{ZrSi}_{2}$.
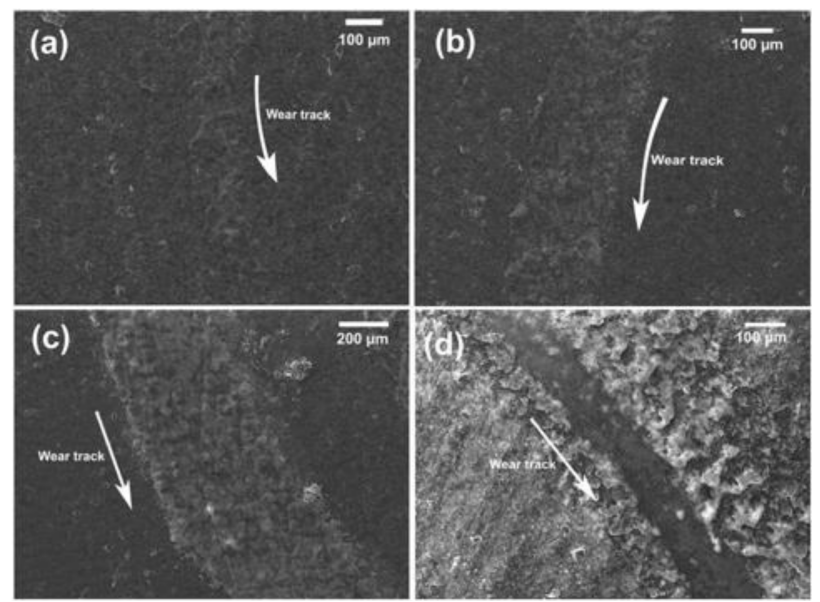

Figure 6. SEM images for SiOC-ZrSi ${ }_{2}$ wear tracks at room temperature for $1 \mathrm{~N}(\mathbf{a}), 2 \mathrm{~N}(\mathbf{b}), 3 \mathrm{~N}(\mathbf{c})$, and $5 \mathrm{~N}(\mathbf{d})$. [5]. 

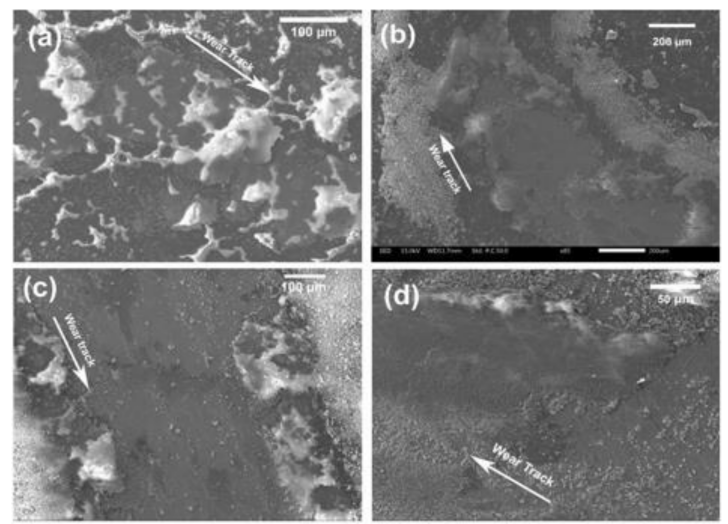

Figure 7. SEM images for SiOC-Ag wear tracks at room temperature for $1 \mathrm{~N}(\mathbf{a}), 2 \mathrm{~N}(\mathbf{b}), 3 \mathrm{~N}(\mathbf{c})$, and $5 \mathrm{~N}(\mathbf{d})$. [5].

The wear tests at various temperatures for $\mathrm{SiOC}-\mathrm{ZrSi}_{2}$, shown in Figure $8 \mathrm{a}-\mathrm{d}$, showed interesting results in that the COFs for tests done at $150{ }^{\circ} \mathrm{C}$ and $300{ }^{\circ} \mathrm{C}$ were higher than those for pure steel on steel contact. After the temperatures were increased to $200{ }^{\circ} \mathrm{C}$ and $400{ }^{\circ} \mathrm{C}$, the COF decreased substantially. The authors attributed this to an initial run-in period, where the decrease in COF is due to the transfer of the coatings to the counter balls. The increase in temperature leads to an increase in the amount of coating transferred; as a result, a shield is created that limits the contact between the subject surface and the ball, leading to a lower COF. The results for the same test done on SiOC-Ag are shown in Figure $8 \mathrm{e}-\mathrm{h}$. Although the COFs start out low at $150{ }^{\circ} \mathrm{C}$ and $200{ }^{\circ} \mathrm{C}$, the $\mathrm{COFs}$ increase substantially for the wear test performed above $300^{\circ} \mathrm{C}$. This was attributed to the excessive softening of the coating at such a high temperature.
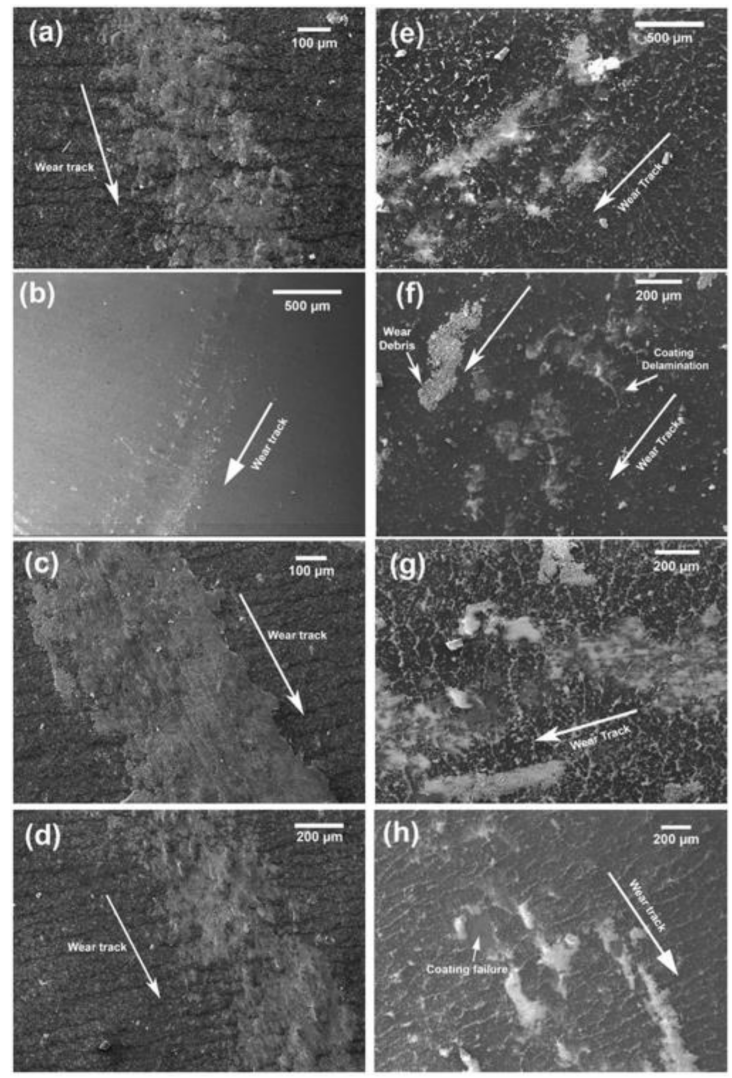

Figure 8. SEM images of wear tracks of both $\mathrm{SiOC} \mathrm{ZrSi}_{2}$ at $150{ }^{\circ} \mathrm{C}(\mathbf{a}), 200{ }^{\circ} \mathrm{C}(\mathbf{b}), 300{ }^{\circ} \mathrm{C}$ (c), and $400{ }^{\circ} \mathrm{C}(\mathbf{d})$ and SiOC-Ag composite coatings at $150{ }^{\circ} \mathrm{C}(\mathbf{e}), 200{ }^{\circ} \mathrm{C}(\mathbf{f}), 300^{\circ} \mathrm{C}(\mathbf{g})$, and $400{ }^{\circ} \mathrm{C}(\mathbf{h})$ at $1 \mathrm{~N}$ load and various temperatures [5]. 
This study focused on the wear tests of two coatings and their strengths and weaknesses. The active filler $\mathrm{ZrSi}_{2}$ allowed the coating to handle higher load bearings, up to $4 \mathrm{~N}$, and enhanced its lubrication properties. The passive filler Ag enhances the lubrication properties of the coating through coating transfer, but it does not apply at high temperatures due to excessive softening. While the coatings hold, there will be reduced friction and less damage on the substrate. The ball-on-disc tribometer is very similar to the SRV tribometer in function but the former does not oscillate so it does not cover an even area like the latter will. Furthermore, the SRV tribometer simulates environments such as the piston reciprocating movements in an engine while the ball-on-disc does not.

\subsection{Brake Materials}

The action of braking is simply the dry sliding wear between two mating surfaces and proper material selection will increase the life of the brakes. The reference [17] shows the applications of the instrument to real-world applications, rather than the more experimental usages seen in the previous sections. The authors opted to perform the tests at various parameters: applied loads from 40 to $160 \mathrm{~N}$ and temperatures from 100 to $300{ }^{\circ} \mathrm{C}$. The choice of the upper temperature limit was oriented to the polymer linings with resin binders. The brake rotor materials are comprised of $38 \%$ ceramic particulate reinforcements and $62 \%$ Al-alloy composites, while traditional brake pads are used.

An initial test to observe the friction coefficients was performed at a constant load of $40 \mathrm{~N}$, an oscillation stroke of $1 \mathrm{~mm}$, and a constant frequency of $80 \mathrm{~Hz}$. The temperatures ranged from 100 to $300^{\circ} \mathrm{C}$, in increments of $50^{\circ} \mathrm{C}$. The initial test consisted of friction fade, shown in Figure 5 in [17], and recovery, in Figure 9 in [17]. The friction fade part is the wear test while the recovery is letting the materials cool. All the temperature tests ran for $10 \mathrm{~min}$ and the end results showed the surfaces rough with E-glass fibers, debris, grooves, and particles spotted throughout, indicating that different areas of the surface were worn at different rates. The groove in Figure 5e in [17] has a length that is close to the preset oscillation stroke of $1 \mathrm{~mm}$, which signifies that the grooves were most likely formed by the protrusions from the indented ceramics instead of the free-rolling abrasive particles.

An increase in temperature results in the breakdown of organic matters in the brake pads, so it should theoretically lead to lower friction coefficients. However, the authors observed an initial increase in friction coefficients, instead, for the former three temperatures, followed by a decrease in friction coefficient for the latter two temperature tests. In Figure 9 in [17], the recovery phase showed an increase in friction coefficient, even surpassing the corresponding values of the fade part. This is known as over recovery, and serious over recovery is impermissible when the brake materials are taken into consideration. Furthermore, as the temperature increases, the specific wear rates will increase as well.

The following wear test was done at a constant temperature of $100^{\circ} \mathrm{C}$ with loads of $40 \mathrm{~N}$ to $160 \mathrm{~N}$, in increments of $40 \mathrm{~N}$; the image results are shown in Figure 9. The test at $40 \mathrm{~N}$ resulted in a small number of grooves and slight damages. The tests done at $80 \mathrm{~N}$ and $120 \mathrm{~N}$ showed a higher number of grooves and the lengths were around $1 \mathrm{~mm}$. The authors concluded that the higher loads caused a deeper penetration of the ceramic protrusions, pushing materials aside and forming the grooves. The most plausible wear mechanism was determined to be a two-body abrasion. For the test at $160 \mathrm{~N}$, significant damage was observed. Conversely, the grooves present (not shown) from the tests done at $250{ }^{\circ} \mathrm{C}$ show less damage at all levels of load. The authors concluded that the adhesive abrasions existed predominantly at higher temperatures due to the presence of more tribofilms. Since the adhesive abrasions are weaker compared to the two-body abrasions, less damage was done. 

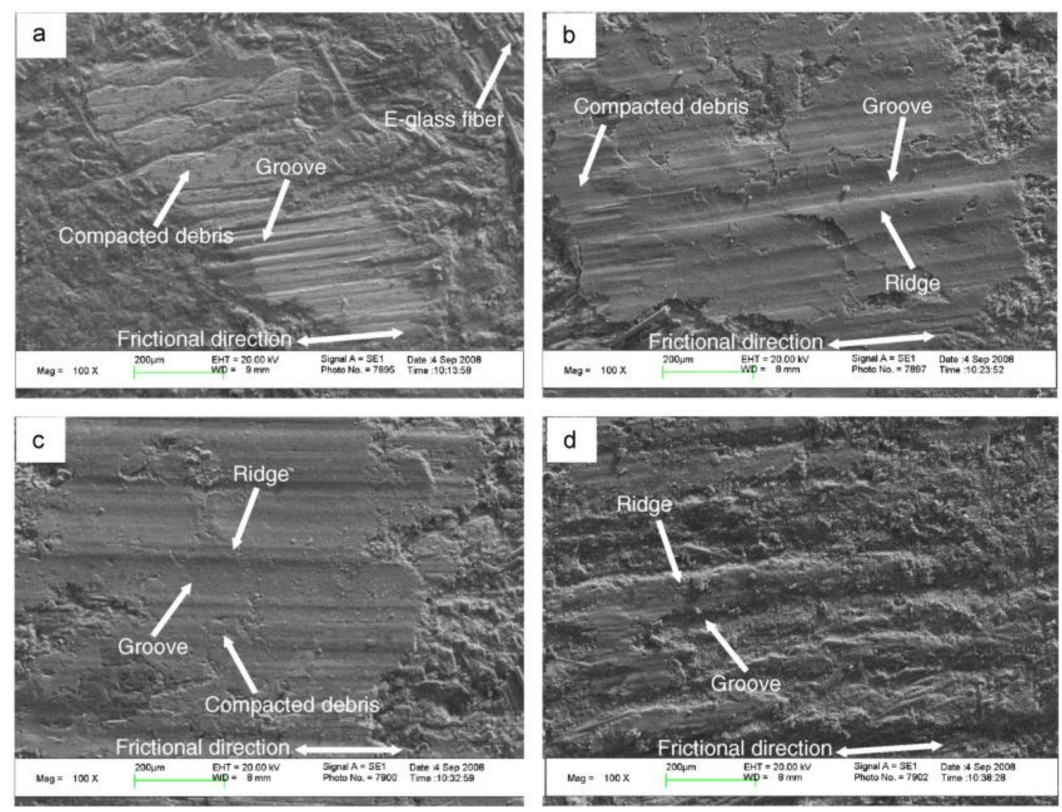

Figure 9. Images for wear test at $100{ }^{\circ} \mathrm{C}, 1 \mathrm{~mm}$ oscillations, $80 \mathrm{~Hz}$ for $40 \mathrm{~N}(\mathbf{a}), 80 \mathrm{~N}$ (b), $120 \mathrm{~N}$ (c), and $160 \mathrm{~N}(\mathbf{d})$ [17].

The friction coefficient and the specific wear rate data for the aforementioned tests are shown in Figures 10 and 11. The friction coefficients for tests at both $100{ }^{\circ} \mathrm{C}$ and $250{ }^{\circ} \mathrm{C}$ decreased as the load increased. However, the coefficients were higher overall for the test at $100{ }^{\circ} \mathrm{C}$. The authors determined that the increased friction is due to the increased amount of $\mathrm{Al}$ and Si particles, which are characterized as severe abrasives. The wear rates for both tests are presented in Figure 11. The two tests surprisingly showed two different results. While the wear rate decreased with increasing load for $250{ }^{\circ} \mathrm{C}$, the opposite was true for $100{ }^{\circ} \mathrm{C}$. This was attributed to the increased tribofilms at higher temperatures with increasing load. This protected the brake materials from wear at higher temperature. The authors attributed the increase in wear rate to the observation that more free particles are present at $100{ }^{\circ} \mathrm{C}$, causing the abrasions to become more intense and the wear resistance decreased as a result.

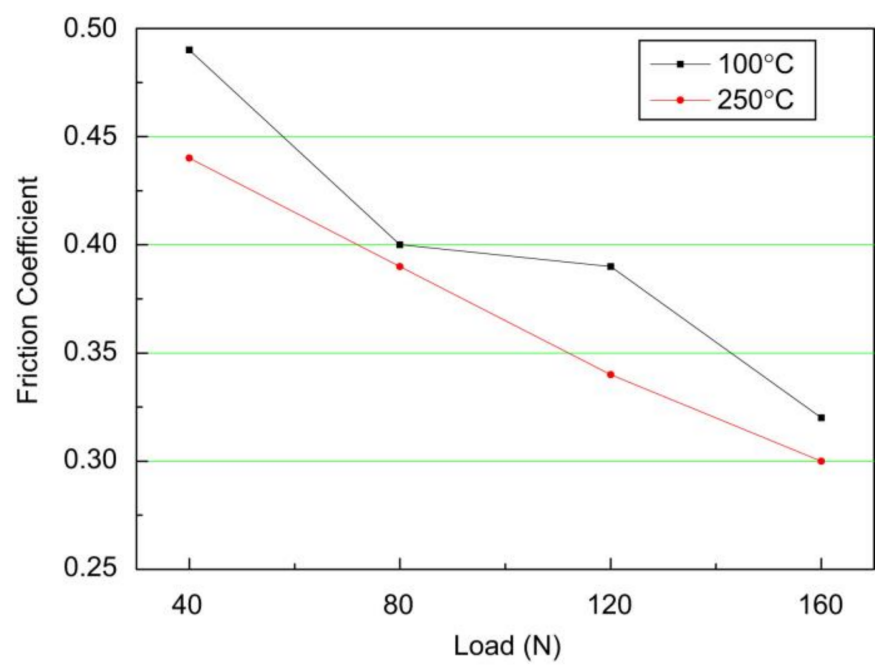

Figure 10. Friction coefficient on the test done at $100{ }^{\circ} \mathrm{C}$ and $250{ }^{\circ} \mathrm{C}, 80 \mathrm{~Hz}$, and various loads [17]. 


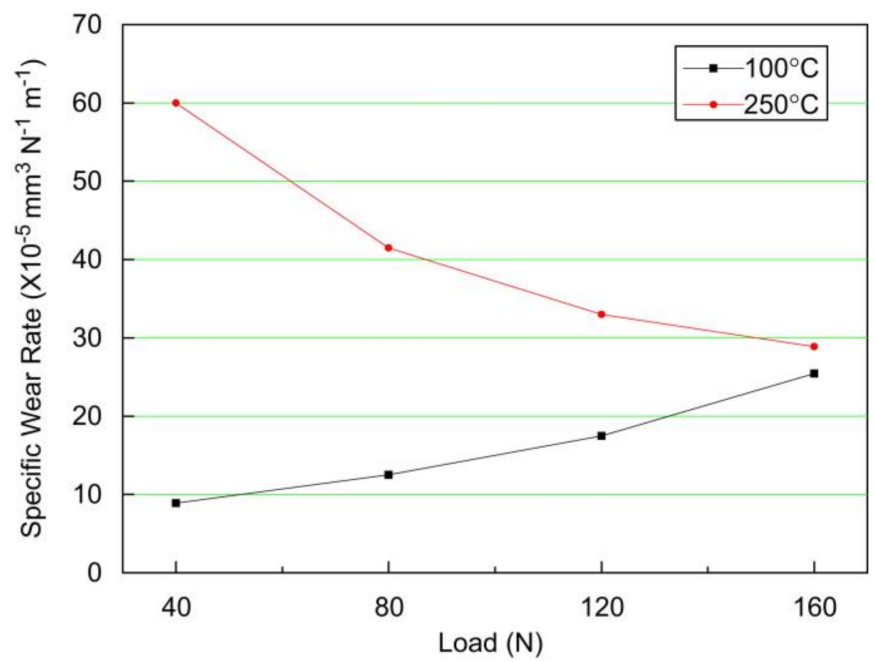

Figure 11. Wear rate on the test done at $100{ }^{\circ} \mathrm{C}$ and $250{ }^{\circ} \mathrm{C}, 80 \mathrm{~Hz}$, and various loads [17].

The tests in this paper were done with an SRV tribometer and the frictional wear of the brake pads were analyzed under various temperatures and loads. A fade test was performed, and the friction coefficients experienced an initial increase before decreasing at higher temperatures; the amount of wear increases with temperature. What followed after was the recovery phase, where over recovery was observed for all temperature levels. Although both tests at 100 and $250{ }^{\circ} \mathrm{C}$ showed a decreasing trend with an increased load, the former showed a higher overall friction coefficient than the latter. The opposite was true for the specific wear rates, where $100{ }^{\circ} \mathrm{C}$ showed a lower rate of loss compared to $250{ }^{\circ} \mathrm{C}$, and the former displayed an increasing trend with load, while the latter showed a decreasing trend. The aforementioned differences are attributed to the increase in free particles at a lower temperature, causing frictional wear to increase. Furthermore, the higher content of $\mathrm{Al}$ and $\mathrm{Si}$, which are severe abrasives, at $100{ }^{\circ} \mathrm{C}$ contributes to the previously mentioned observation.

\subsection{Tool Steels}

High-strength steels have become more prominent in automobiles, as steels are favored for their properties. Some of these steels, especially more complex ones, are shaped through the usage of hot-metal forming. In certain scenarios, Al-Si-coatings are utilized to keep the shape of the uniform during the aforementioned process. However, since the interaction between this coating and tool steels is not yet well-known in practical settings, in [18], the authors formulated a test to further the knowledge on this specific topic. To this extent, the authors used an SRV tribometer for testing in two parts: one where temperature steadily increased from 40 to $800{ }^{\circ} \mathrm{C}$, and the other where the temperatures remained constant at 40,400 , and $800^{\circ} \mathrm{C}$. Three different tool steel pins were used with Al-Si-coated steels discs for simulating the frictional and wear effects that would result from actual scenarios. The wear tests were performed at a load of $50 \mathrm{~N}$, stroke of $1 \mathrm{~mm}$, and a frequency of $50 \mathrm{~Hz}$.

The first tests done were at increasing temperatures, from 40 to $800{ }^{\circ} \mathrm{C}$, at a steady rate with three plasma-nitrided (PN) tool steels (TS). For the PN (Figure 12) and untreated (UT) tests (Figure 2 in [18]), TS1, TS2, and TS3 all showed similar trends. The coefficient of friction for both tests showed an initial value of around 0.8 before decreasing to 0.6 shortly after the tests started. The COFs reached a maximum of approximately 1.35 , before slowly decreasing over the rest of the test, while an increase in friction was noticed at above $1000^{\circ} \mathrm{C}$. However, when the overall COFs are considered, the treated tool steels had lower values. In Figure 13, the wear rates of TS1 and TS2 PN showed similar wear rates, while TS3 PN showed a much lower wear rate. For the TS1 and TS2 UT test the results (not shown) were irregular due to scattering in the results, resulting in a negative wear 
rate (gaining of particles). However, TS3 UT showed a higher wear rate, indicating that plasma-nitraded tool steel has a higher resistance to wear.

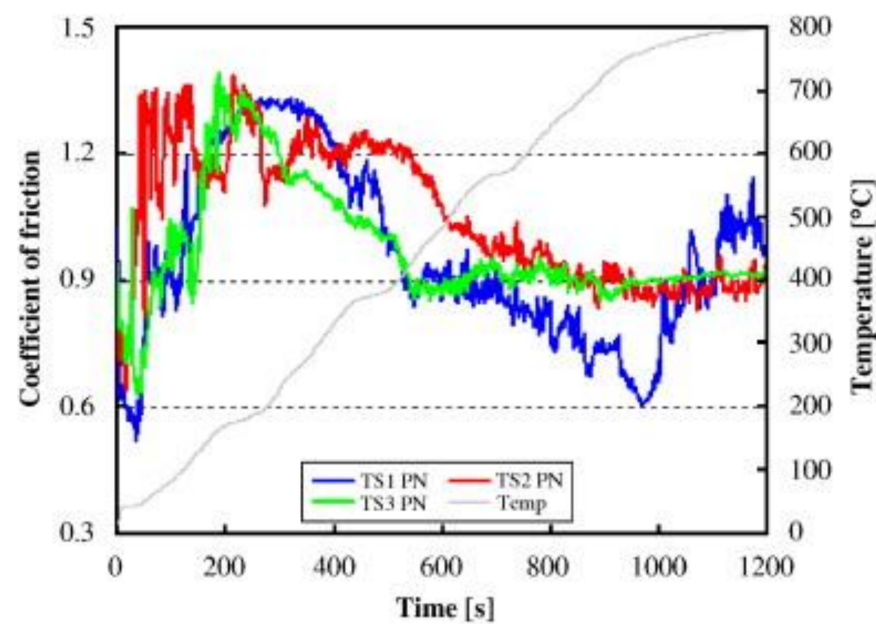

Figure 12. Coefficient of friction over a steady temperature increase from 40 to $800{ }^{\circ} \mathrm{C}$ using plasmanitrided tool steel on Al-Si-coated steel [18].

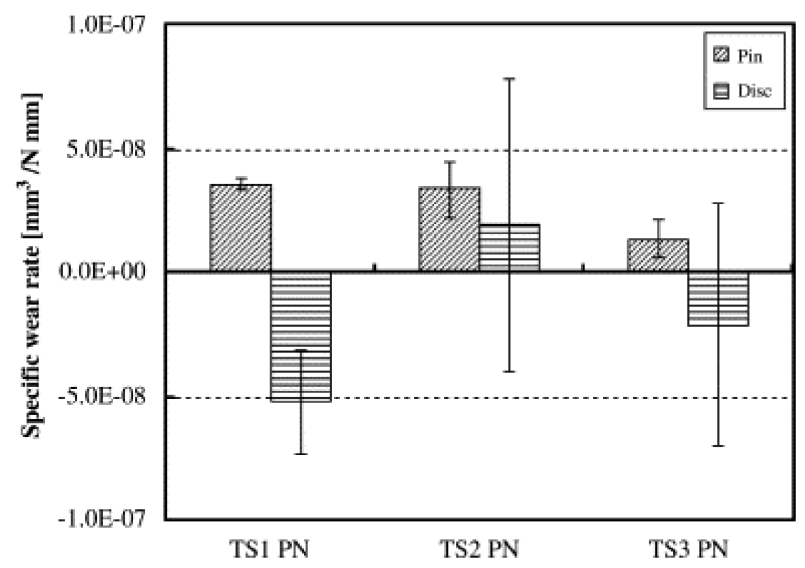

Figure 13. Specific wear rates for steady temperature increase from 40 to $800^{\circ} \mathrm{C}$ using plasma-nitrided tool steel on Al-Si-coated steel [18].

The test done at a constant $40^{\circ} \mathrm{C}$ was performed by using plasma-nitrided tool steels, shown in Figure 14. The other two tests, done at $400{ }^{\circ} \mathrm{C}$ and $800{ }^{\circ} \mathrm{C}$, are Figures 4 and 5 in [18], respectively. The COFs for TS1, TS2, and TS3 for $40^{\circ} \mathrm{C}$ showed a steady increase from an initial value of 0.6 until it reached approximately 1.3 at $200 \mathrm{~s}$, and it plateaued from there. However, for the test at $400{ }^{\circ} \mathrm{C}$, the initial values were regular, until it stabilized at $200 \mathrm{~s}$ around 1.0, before steadily declining until hitting 0.8 for COFs. The test at $800{ }^{\circ} \mathrm{C}$ showed different trend patterns from the former two tests. TS1 started around 0.7, before stabilizing around 0.9; by the end of the test, however, the COF increased up to 1.2. For TS2, it also initially began at 0.7 , before reaching 1.0 and then falling back down to plateau at 0.9 . The values for TS3 began around 1.0 and declined to hover around 0.9 ; similar to TS1, TS3 also experienced an increase near the end of the test to a max of 1.45 , falling down to 0.9 at the end. 


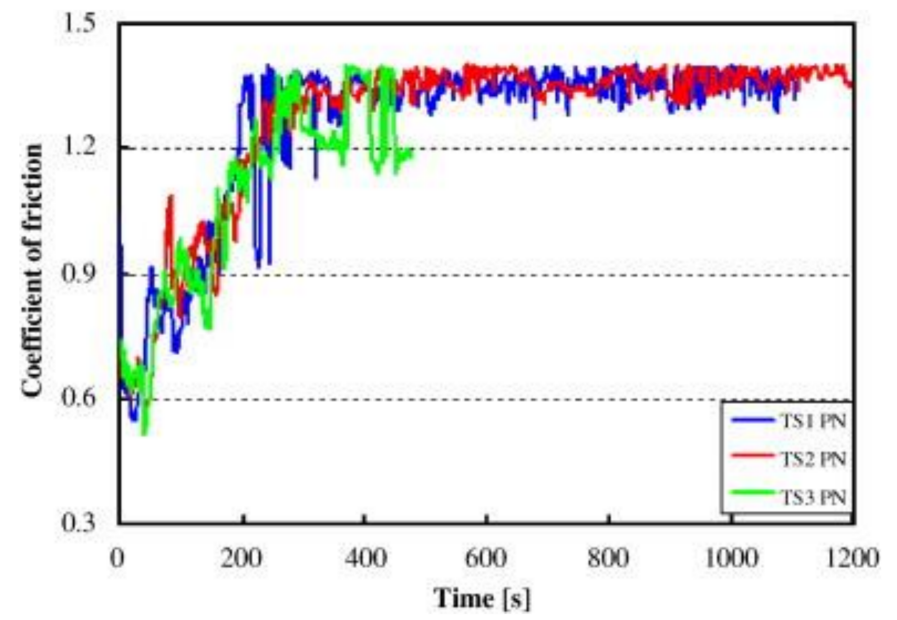

Figure 14. Coefficient of friction over time at $40{ }^{\circ} \mathrm{C}$, plasma-nitrided tool steel on Al-Si-coated high-strength steel [18].

The specific wear rates were also recorded for the three constant temperatures. At $40{ }^{\circ} \mathrm{C}$, all three tool steels had very low wear rates, but the opposite was true for the Al-Si-coated steel. Although the wear rates for the disc were much higher, TS3 still showed the least specific wear rate for either the pin or the disc out of the three. At $400{ }^{\circ} \mathrm{C}$ the discs all display a higher wear rate than compared to that of $40^{\circ} \mathrm{C}$. The wear rates of the disc were similar for TS2 and TS3, but lower than that for TS1. Finally, for the test at $800{ }^{\circ} \mathrm{C}$, the wear rates for the pins were all very close. However, while TS1 and TS2 did not have much of a difference from the ones at $400{ }^{\circ} \mathrm{C}$, TS3 values were almost halved. The disc, on the other hand, showed negative wear rates for TS2 and TS3.

The purpose of these tests was to understand the real-world effects of using tool steels on Al-Si-coated high-strength steels in automobiles. To this extent, two tests were conducted-one with a steady increase of temperature and the other at three constant temperatures. The COF values for the steady incline in temperature showed an initial high $\mathrm{COF}$, then lower in the middle, and finally either increasing or plateauing at the end of the test. This result is supported by the individual temperature tests, which demonstrated highest friction coefficients at $40{ }^{\circ} \mathrm{C}$, lowest at $400{ }^{\circ} \mathrm{C}$, and mixed results at $800{ }^{\circ} \mathrm{C}$. The specific wear rates data displayed inconclusive data for TS1 and TS2 PN, as it showed a weight gain instead of a decrease for the non-constant temperature test. At $40{ }^{\circ} \mathrm{C}$, low wear rate was observed for all three tool steels, while the Al-Si-coated disc had high wear rates. Although the specific wear rates for the pins were also similar for all three tool steels at $800^{\circ} \mathrm{C}$, TS3 showed a decrease in the wear rate of approximately a factor of two compared to its corresponding value in the test at $400{ }^{\circ} \mathrm{C}$. The two-part tests done in this paper showed a dependency of frictional wear on temperature, with higher friction at lower temperatures, and lowest friction at medium temperatures.

\subsection{Drilling}

Drilling is a common process necessary for a plethora of operations. However, when the drills are used for an extended period of time, an elevated temperature is reached, and wear is increased as well. Drills are meant for multiuse purposes, so reducing their vulnerability to frictional wear will allow cutbacks on costs for new drills. In the paper "On the tribology and micro-drilling performance of TiN/AIN nanolayer coatings" [19], the authors used an SRV tribometer to quantify the function of the coatings. The tests had parameters of a load of $50 \mathrm{~N}$, stroke of $0.2 \mathrm{~mm}, 10 \mathrm{~Hz}$, and a total of 6 min for each run. The tests were performed on an SRV tribometer and without lubricants (dry contact), and the setup diagram is shown in Figure 15 shown below. The coatings were created through the use of technology that allowed the "high-speed reactive pulsed-arc plasma aided physical 
vapor deposition," and the periods of the nanolayers were also controlled by managing the deposition parameters.

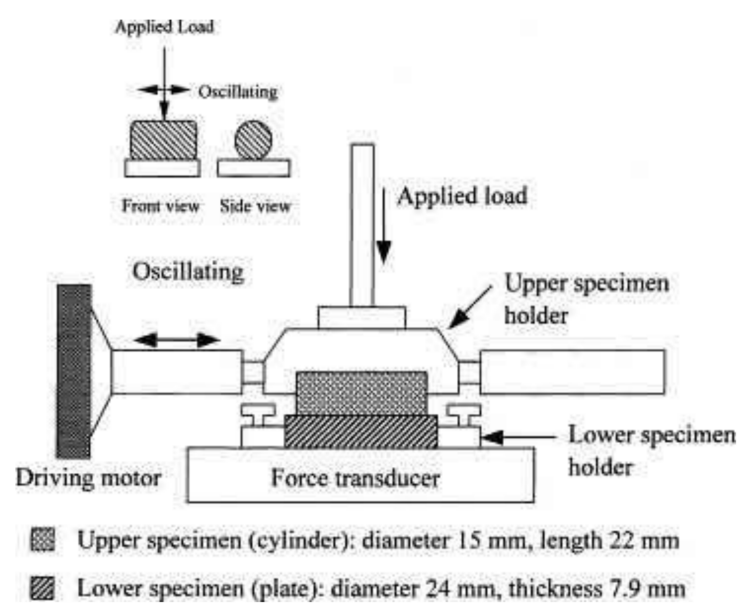

Figure 15. Schematic of the tribometer testing [19].

The coatings are made of three elements, N, Ti, and Al. The " $\mathrm{R}$ " coatings contain lower $\mathrm{Al}$ content and period when compared to the "N" coatings. From R5 to R1, the period increases while no specific patterns are found from N20 to N10.

The tests done with the SRV tribometer were observed for the wear depths and the COFs of the various nanocoatings. All eleven coatings, along with uncoated drills for comparison, were subjected to the wear test and the data are shown in Figure 16. For the COFs, the highest number of the coated was approximately 1.3 and the lowest around 1. The highest COF overall was the uncoated, which reached almost 1.4. The R1-5 coatings had lower friction coefficients when compared to the " $\mathrm{N}$ " coatings. This trend is also observed for the wear depth of the specimen. The " $R$ " coatings also showed lower wear depth, with R3-5 showing significantly lower wear depth compared to all its other counterparts, indicating superior wear resistance. Although the uncoated material's wear depth is higher as expected, the wear depth of the N10-coated specimen was an entire unit higher than that for the uncoated. Although the TiN coated materials had a similar COF, its wear depth is almost three times that of the R3-5-coated items.

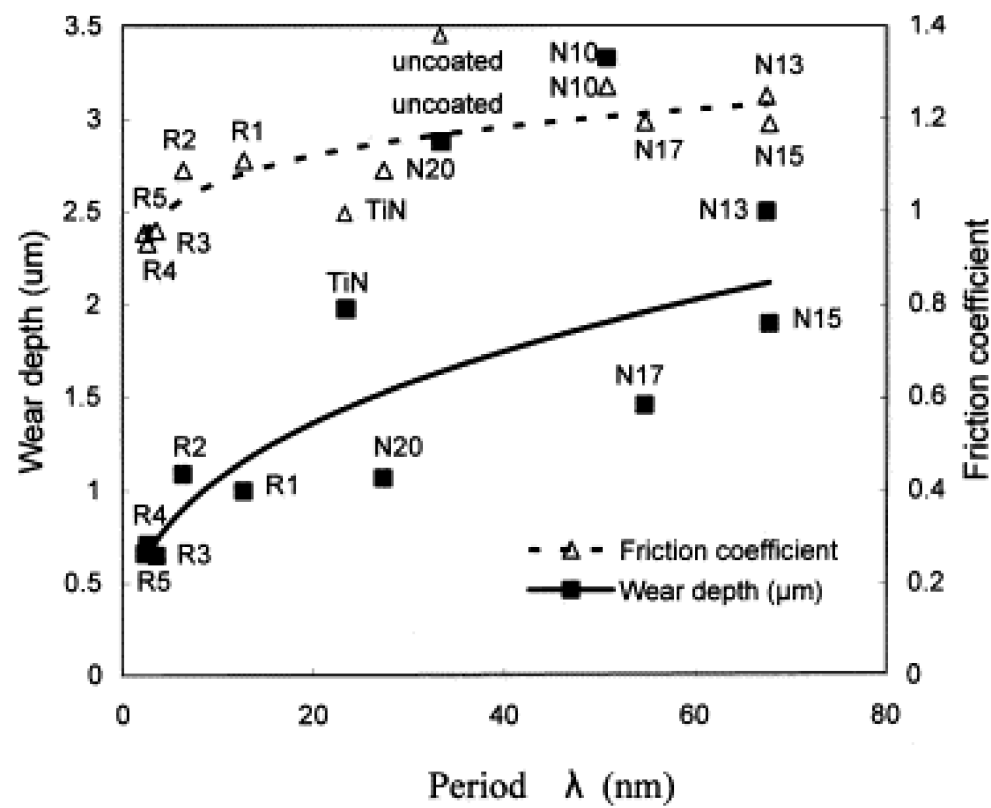

Figure 16. Wear depth and friction coefficient based on period [19]. 
As R3-5 coatings have shown to have excellent anti-wear properties, they were coated directly on the drill bits for observation on direct applications. Uncoated and TiN coated drills were added for comparison and the results are displayed in Figure 17. As expected, all the drills, whether coated or uncoated, experienced higher wear at higher number of holes drilled. The highest corner wear of the drills occurred on the uncoated drill, followed by the TiN coated one having the second highest wear. The R3-5 nanolayer coatings performed the best out of the five, with R4 performing slight better than its other two counterparts. However, the differences are small, and the three coatings can be considered to have almost equal efficacy on preventing wear. The morphologies of the hole made by drills after drilling 20,000 holes are a comparison between the R4-coated drill bit, and the TiN-coated drill bit. The hole created by the R4-coated drill showed a smoother boundary than compared to that made by the TiN-coated drill. When compared to the drill hole of the uncoated (not shown), both the TiN and the R4 showed better results.

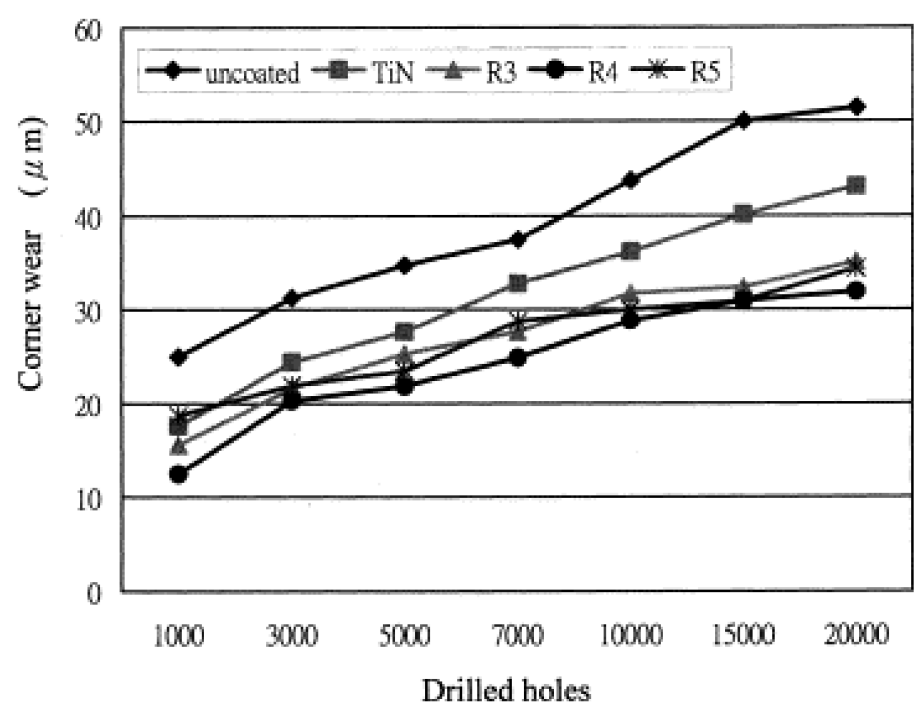

Figure 17. Wear of nanolayer-coated drills based on number of holes drilled (Adapted from [19]).

Although these nanolayer coatings were tested on micro-drills, the results indicate that these coatings can be applied in practical settings with actual machineries. As the period decreases, the wear resistance increases; thus, the coatings with the lowest period, R3, R4, and R5 showed the best results. The wear depths as well as the friction coefficients were lowest for the R3-5 coatings. Once these three coatings were applied to drill bits for actual application, the results were consistent with test data. The coatings showed favorable corner wear and the morphology of the drilled holes also showed that the R4-coated drill bit having maintained its shape better as seen by the smoother drill boundary. Having the coatings on a larger drill for industrial applications is achievable and can improve wear resistance greatly.

\subsection{Additional Literature}

In addition to the aforementioned tests, a multitude of other applications, whether for research or direct implications, can be made through the usage of an SRV tribosystem. Application-oriented testing, as the name suggests, focuses on tests for the purpose of obtaining results that have a more direct and immediate impact. Research-oriented testing, on the other hand, focuses more on the discovery and learning process. The following sections will contain both research-based and application-based literature, and one section will comprise of tests performed with the SRV tribometer, while the other will be of new of general applications or discoveries made in the field. 


\subsubsection{More SRV Applications/Tests}

The tests that are oriented toward practical applications need to mimic actual conditions. Therefore, to ensure the applicability of the results, the parts used must be as close to the actual counterparts as possible [20]. In a paper published by Dr. Mathias Woydt and Dr. Ameneh Schneider [20], several examples of practical applications are given. One such example is the testing of chassis joints. The friction and wear of the greased joints need to be recorded to ensure the proper function of the plastic suspension joints and grease. The next topic is on the evaluation of test methods of synchronizers, where manual transmission fluids (MTF) and other materials are investigated. Furthermore, SINOPEC has created a method to both assist and make the MTF development process more efficient. Thirdly, a vane pump is a common part of hydraulic systems and it is not exempt from tribological observations. The hydraulic oils are analyzed for their pressure, friction, and wear properties using known, existing methods. Further tests that extended the tribological properties of the oil allowed the expansion on the formulation of the hydraulic oils.

Pistons and their related parts are an important part of an engine. In addition, however, the pistons also make up approximately $50 \%$ of all internal engine wears; the cost of a full engine test has been increasing due to the ever-complicating test matrices and technological advances, along with the increasing number of materials required for a proper operation [20]. Tests done on the load carrying capacity (LCC), showed that the LCC is highest when the temperatures are low and the oil supply rate is higher, and the opposite is true when the temperatures are high and the oil supply is low, as can be seen in Figure 18 [20,21]. When the load is increased on top of increasing temperature and decreasing oil supply, the COF goes from stable to unstable [21]. Further data have been achieved on the frictional wear of the piston rings/cylinders by using SRV tests on the pistons and the pistons with coatings/lubricants as an experimental model tool [22].

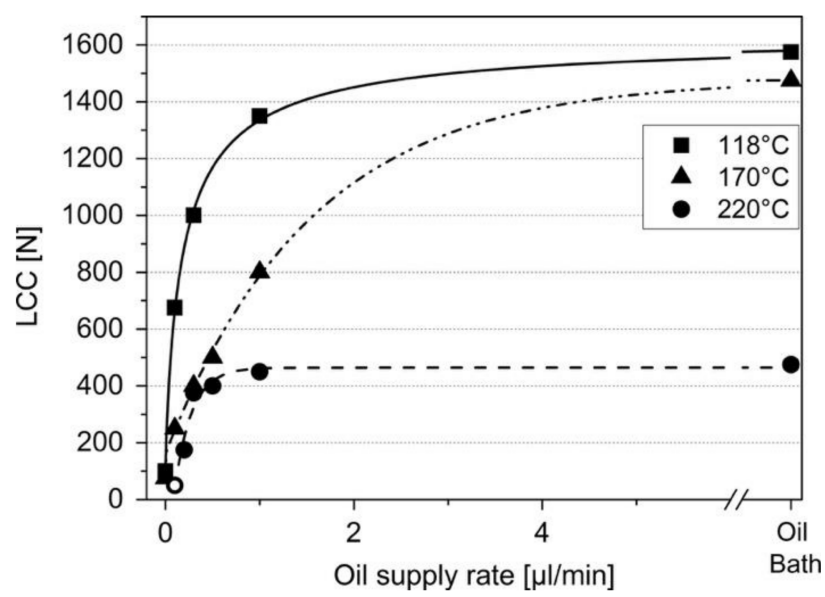

Figure 18. Load carrying capacity (LCC) value at different temperatures with respect to oil supply rate [21].

Thin films have proven to be useful in helping to improve the properties of the substrate, such as sustaining high loads and providing resistance to wear [23]. The most common way to test the adhesion of the thin films is according to ASTM or DIN standards, which is where a diamond stylus is used over the target at linearly increasing loads until the critical load is reached [20]. However, a new method has been recently implemented through the usage of reciprocating tribometers such as the SRV, and the conditions of delamination were studied $[20,24]$. The increase in friction during testing is attributed to two main factors: the delamination of the coating, or the accumulation of debris from the breakdown of the film. Furthermore, recent studies have attempted to incorporate nanocrystalline diamonds (NCD) in advanced automotive tribosystems $[20,25]$ due to the known enhancement properties of the NCDs such as low surface roughness and low compressive stress [25]. 
In a recent study [3] on temperature effects on friction and wear properties of steel against steel dry contact, AISI 52100 bearing steel balls were tested with AISH H13 steel discs due to their wide application in different engineering fields. The frequency, load, and stroke of the tribometer was set to $8 \mathrm{~Hz}, 15 \mathrm{~N}$, and $2.5 \mathrm{~mm}$, respectively. The time frame of the tests was at $0.5,4,8$, or $15 \mathrm{~h}$, and the temperature ranged from room temperature (RT) to $500{ }^{\circ} \mathrm{C}$. Two friction regimes were present at temperatures above $300{ }^{\circ} \mathrm{C}$ and test times at $4 \mathrm{~h}$ or above. The first friction regime relates to the wear of the ball and disc, while the second regime, a reduction in wear and friction was observed. Moreover, as displayed in Figure 19, at temperatures above $300^{\circ} \mathrm{C}$, the 521000 ball experienced mass loss while the H13 disc witnessed mass gain.

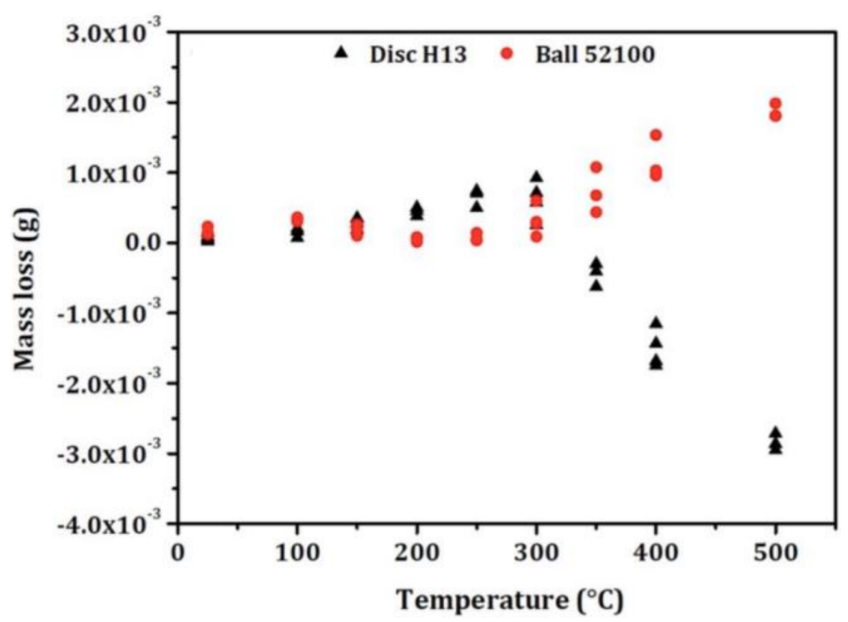

Figure 19. Mass loss of ball and disc with respect to temperature [3].

To ensure the longevity of mechanical parts that are subjected to high temperatures and wear, a coating that can withstand high temperatures and extended wear must be applied [26]. One such coating is the $\mathrm{Co}+\mathrm{Cr}_{2} \mathrm{O}_{3}$ coating, which has superior friction protection at high temperatures. The wear at low temperatures of the coating is low due to the cobalt matrix. As the temperature increases up to $100^{\circ} \mathrm{C}$, the wear also increases. As the temperature reaches $200^{\circ} \mathrm{C}$, however, a glaze layer starts to form, reducing the wear on the surfaces. At $300{ }^{\circ} \mathrm{C}$, the glaze layer is completely formed, preventing any adhesive wear from occurring. When increased above $300^{\circ} \mathrm{C}$, the wear rate constantly remains low up until the tested $700{ }^{\circ} \mathrm{C}$.

Fretting wear is often considered as a plague in fields such as aeronautics and nuclear engineering [27]. Multiple studies have investigated the frictional and wear impact of high temperatures on various types of steels at fretting conditions, and they have determined that once a certain temperature has been reached, there is a sharp decline in the wear rate [27-31]. Another study [32] did a triple heat treatment (THT) on Inconel X-750 before subjecting it to the same wear test conditions as its untreated counterpart at three temperatures: $25^{\circ} \mathrm{C}, 315^{\circ} \mathrm{C}$, and $650^{\circ} \mathrm{C}$. The untreated materials displayed severe wear and transfer of materials between the pin and the disc, while the specimen that underwent THT showed a much more stable wear representation.

Up until recently, the Fafnir fretting wear test has been in use for fretting wear measurements [33]. However, that test has recently been determined to produce extremely large differences from test to test, anywhere from a relative standard deviation of $27 \%$ to $84 \%$. The disparity between batches of bearings is certainly one, but not the only, attribute that is causing the variation. Currently, experts from multiple companies are compiling the data necessary in order to reduce the variations in the test.

\subsubsection{Tribological Advancements/Discoveries}

The strive for better lubrication for wear and friction protection has been happening for a long time. However, this strive for improvement has not stopped and research on 
elevated efficiency and efficacy on wear resistance is ever increasing to meet the new demands of the more complex tribosystems that exist today. To this extent, liquid and solid lubricants in the form of thin films, soft metals, and nanotextured coatings have been innovated [34]. In addition, improvements in laser texturing have also improved the wear properties of various surfaces.

Solid lubricants are the most prominent in part due to them being one of the longest used in the industry. Some common examples of solid lubricants are molybdenum disulfide, graphite, soft metals, specific types of polymers, and even forms of oxides [34,35]. From these lubricants, some are able to be directly used on the surfaces through processes including ion-beam-assisted deposition and ion plating [34,36,37], while the others are constructed by using methods such as molecular grafting, vapor phase deposition, and sol gel $[34,38,39]$. One example of a lubricant directly applied on surfaces is soft metallic films. These films have the ability to lower the COFs significantly when dry sliding occurs [34]. When subjected to high temperature sliding tests and in the presence of lubricating oils, the friction coefficient can be reduced even further [34,40,41].

Lamellar solid lubricants, such as the boric acid thin film, are another type of coating that have proven themselves to have very beneficial applications. As can be seen in Figure 20, the $\mathrm{B}_{4} \mathrm{C}$ treated by boric acid had a significantly lower friction coefficient when compared to the control $\mathrm{B}_{4} \mathrm{C}$ [34]. As a result of its wear and friction resistant properties, it is an amazing choice for applications in machineries with sliding wear. The reason why boric acid has such an excellent anti-wear and anti-friction property is due to the fact that it has a lamellar crystalline structure [34,42].

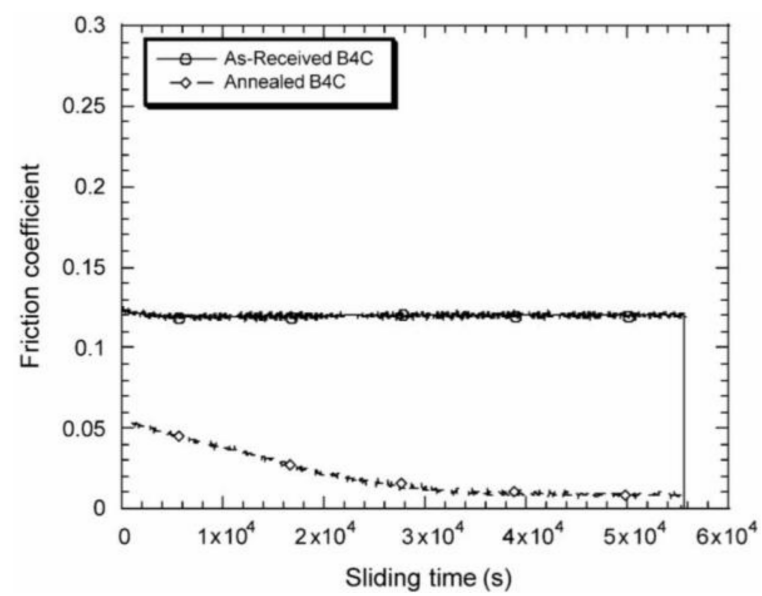

Figure 20. Coefficients of friction (COFs) for pure $\mathrm{B}_{4} \mathrm{C}$ and boric acid coated $\mathrm{B}_{4} \mathrm{C}$ with respect to wear time [34].

Carbon films are well-known and provide impressive friction and wear protection. The diamond-like carbon (DLC) coating, specifically, can provide a COF lower than 0.01 and a wear rate less than $10^{-10} \mathrm{~mm}^{3} / \mathrm{N} \mathrm{m}$ in inert-gas or vacuum environments [34,43]. Further testing has also revealed that when the DLC films are used in lubricant sliding conditions as well, the results may also be very remarkable $[34,44,45]$. The latest results have also shown that in addition to its superior wear properties, the coating can be enhanced even further when the synergy between the DLC and the lubricating oils is maximized [34,46]. Figure 21 shows the efficacy of the coatings, which display friction coefficients being magnitudes lower than their uncoated counterparts. 


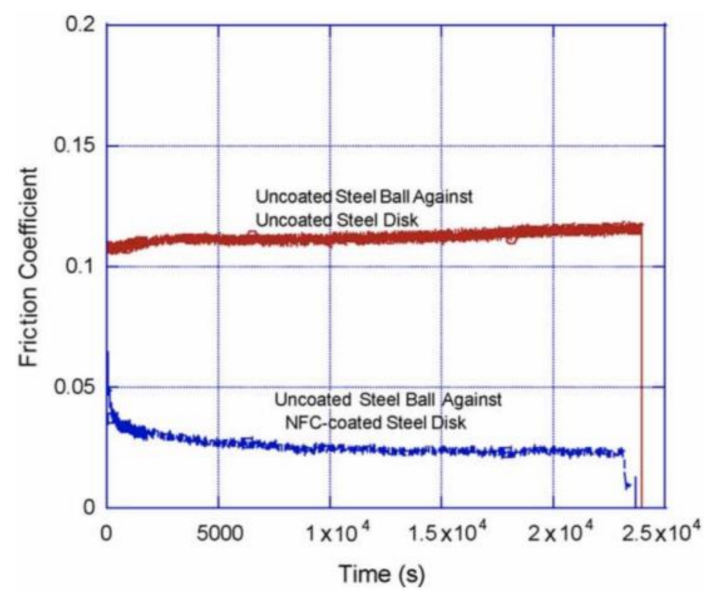

Figure 21. COFs of uncoated steel disc vs. coated steel disc with respect to time [34].

Due in part to the advancements in nanotechnology, the development of nanostructured coatings has also increased drastically. These structures are quite varied in that while some contain metallic and ceramic phases, others are comprised of nano-multilayers or superlattices $[34,37,47,48]$. Nanostructures usually have unique properties, and the coatings that are formulated from them are no exception. Their applications are very diverse and specific coatings can be used for specific scenarios. For example, these types of coatings can provide added electrical conductivity on top of wear reduction and increased hardness [34].

The next topic is not a coating or lubricant, but rather a method for preventing friction and wear that is directly applied onto the material surfaces, which is achieved through the usage of lasers. This method has been used on machine parts, such as mechanical seals and bearings, to improve their properties for wear resistance [34]. Pits and dimples have been created using laser texturing, which results in enhanced hydrodynamic of the surfaces, resulting in an augmented lubrication performance. Moreover, laser texturing can be used in conjunction with other methods, such as the aforementioned DLC coating $[34,49,50]$. As a result, the already excellent DLC coating can be further improved to protect the tribological system from further wear.

Hot stamping allows high strength steels, such as 22MnB5 tool steel, to be morphed into complex shapes. This process was evaluated for its tribological properties and the test process was simulated to be as close to actual hot stamping conditions as possible by using tool steel for the stamp [8]. The test parameters are shown in Table 1. The results of the sliding velocity test indicated that the sliding velocity does not greatly affect the friction coefficients but does negatively impact adhesive wear at lower speeds. As the contact pressure increases, the COF increases as well, and the wear process changes from ploughing wear to plastic deformation wear. The lubricant tests utilized $\mathrm{MoS}_{2}$ as the lubricant and the sample with $\mathrm{MoS}_{2}$ has a lower COF than the one without, due to the lubricant adjusting itself to be parallel with the wear direction, thereby decreasing the friction $[8,51]$.

Table 1. Testing parameters for measuring COF [8].

\begin{tabular}{ccccc}
\hline Test Parameters & $\begin{array}{c}\text { Temperature } \\
\left({ }^{\circ} \mathbf{C}\right)\end{array}$ & $\begin{array}{c}\text { Sliding Velocity } \\
(\mathbf{m m} / \mathbf{s})\end{array}$ & $\begin{array}{c}\text { Contact } \\
\text { Pressure }(\mathbf{M p a})\end{array}$ & $\begin{array}{c}\text { Lubrication } \\
\text { Condition }\end{array}$ \\
\hline $\begin{array}{c}\text { Temperature } \\
\text { tests }\end{array}$ & $650,750,850$ & 50 & 8 & Dry \\
$\begin{array}{c}\text { Sliding velocity } \\
\text { test }\end{array}$ & 750 & $25,50,75$ & 8 & Dry \\
$\begin{array}{c}\text { Contact pressure } \\
\text { test }\end{array}$ & 750 & 50 & 4,8 & Dry \\
Lubrication test & 750 & 50 & 8 & Dry, lubricated \\
\hline
\end{tabular}


The main purpose of a hot strip mill is to heat up the unfinished steels to their rolling temperature, before rolling them thinner and longer to the desired dimensions. During this process, an oxide-on-oxide interaction occurs between the steel and the work rolls and the frictional damage of this interaction needs to be understood to regulate the damage that might be caused [52]. However, it is impossible to completely eliminate the friction resulting from the oxide-oxide interaction, as friction is what drives the process in a hot strip mill [53]. The entire test consists of four stages, and the process can be seen in Figure 22. The first stage is the oxidation of the pin surface used in the tribometer, which saw an increase in COF. The second stage is the start of the third body by the addition of oxides to the testing disc, resulting in a slight friction coefficient decrease. The third stage is when the process is left to run, and the COF is on the rise again. The fourth stage is after more than an hour of testing, where the wear has stabilized and there is not much change in the friction coefficient. The increase in friction is due to the wear slowly becoming iron oxide-on-iron oxide, and when both pieces are finally coated with iron oxide, the wear becomes constant.

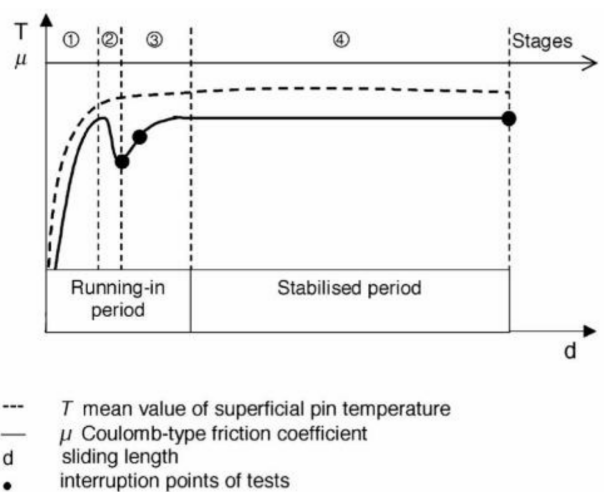

Figure 22. COF throughout the test, separated into four stages, with respect to sliding distance [52].

\section{Conclusions}

Monitoring the invaluable tribological quantities of friction and wear throughout the use of a tribosystem can reveal important information regarding how the system may gradually change, particularly for high temperature tribology applications.

High temperature tribometers were shown to be excellent analytical tools when investigating tribolayers that are formed due to oxidation and wear at high temperatures and how these layers may vary at different temperatures. These tribolayers essentially evolve as the wear process occurs and multiple layers are formed as a result. Unlike at room temperature, many types of layers are formed at high temperatures with zones 3 and 1, the glaze layer, of the disc consisting of a similar composition as the materials of the pin. The result of these tribolayers is that the properties not only minimize wear but also enable a self-healing capability through the integration of wear debris whenever a gap appears during wear [2]. Furthermore, the applicability of these tribometers with regards to high-temperature lubricious coatings was shown to be effective in determining friction and wear behavior. Passive and active fillers were used to improve the properties of the coatings and the two types showed differing results. The active filler $\mathrm{ZrSi}_{2}$ allows the coating to handle higher loads and increases lubricity. On the other hand, the passive filler $\mathrm{Ag}$ offers a greater lubrication property than $\mathrm{ZrSi}_{2}$; however, as the temperature increases beyond $300{ }^{\circ} \mathrm{C}$, excessive softening occurs and greatly decreases that property [5]. These tribometers have been applied to many functional parts of a vehicle including brake pads, where these tribometers have been used to determine how the friction and wear properties may change in braking systems as a function of temperature. At constant load and oscillation frequency, the specific wear rates increase as functions of temperature, but the friction coefficients experienced an initial increase followed by a decrease for the later parts of the test. For the tests done at $100^{\circ} \mathrm{C}$ and $250^{\circ} \mathrm{C}$, the oscillation frequency remained constant while the loads increased. While a downward trend was observed for the friction 
coefficients at both $100{ }^{\circ} \mathrm{C}$ and $250{ }^{\circ} \mathrm{C}$, the specific wear rates experienced an opposite trend, relative to each other, as the loads increased [17].

Author Contributions: Conceptualization, R.S., R.C., M.W., C.B., J.J., and P.I.; formal analysis, R.C. and P.I.; writing—original draft preparation, R.C. and P.I.; writing—review and editing, R.S., M.W., C.B., and J.J.; supervision, R.S., M.W., C.B., and J.J.; All authors have read and agreed to the published version of the manuscript.

Funding: This research received no external funding.

Conflicts of Interest: The authors declare no conflict of interest.

\section{References}

1. Woydt, M. Materials based concepts for an oil free engine. In New Directions in Tribology; Hutchings, I.M., Ed.; First World Tribology Congress: London, UK, 1997; pp. 459-468, ISBN 1-86058-099-8.

2. Rynio, C.; Hattendorf, H.; Klöwer, J.; Eggeler, G. The evolution of tribolayers during high temperature sliding wear. Wear 2014, 315, 1-10. [CrossRef]

3. Durango, A.Z.; Cano, M.F.; Souza, R.M.; Sinatora, A. Effect of temperature on friction and wear under reciprocating sliding of AISI 52100 against AISI H13 steel. Mater. Perform. Charact. 2020, 9, 365-378. [CrossRef]

4. Lewis, R.; Dwyer-Joyce, R.S. Combating Automotive Engine Valve Recession: A Case Study. Tribol. Lubr. Technol. 2003, 59, 48-51.

5. Alvi, S.A.; Akhtar, F. High temperature tribology of polymer derived ceramic composite coatings. Sci. Rep. 2018, 8, 15105. [CrossRef] [PubMed]

6. Woydt, M. Review on Lubricious Oxides and Their Practical Importance. In Handbook of Surface Modifications and Processing: Physical \& Chemical Tribological Methodologies; Totten, G.E., Ed.; Marcel Dekker: New York, NY, USA, 2004; ISBN 0-9247-4872-7.

7. Hardell, J. High Temperature Tribology of High Strength Boron Steel and Tool Steels. Ph.D. Thesis, Luleå University of Technology, Luleå, Sweden, June 2017. Available online: http:/ / epubl.1tu.se/1402-1757/2007/36 (accessed on 13 July 2020).

8. Mu, Y.; Wang, B.; Huang, M.; Zhou, J.; Li, X. Investigation on tribological characteristics of boron steel 22MnB5-tool steel H13 tribopair at high temperature. Proc. Inst. Mech. Eng. Part J J. Eng. Tribol. 2017, 231, 165-175. [CrossRef]

9. Stott, F.H. High-temperature sliding wear of metals. Tribol. Int. 2002, 35, 489-495. [CrossRef]

10. Chang, Y.N.; Wei, F.I. High temperature oxidation of low alloy steels. J. Mater. Sci. 1989, 24, 14-22. [CrossRef]

11. Stott, F.H. The influence of oxidation on the wear of metals and alloys. In New Directions in Tribology; Hutchings, I.M., Ed.; First World Tribology Congress: London, UK, 1997; pp. 391-401, ISBN 1-86058-099-8.

12. Gardos, M.N. Magnéli phases of anion-deficient rutile as lubricious oxides. Part I. Tribological behavior of 276 single-crystal and polycrystalline rutile $\left(\mathrm{Ti}_{\mathrm{n}} \mathrm{O}_{2 \mathrm{n}-1}\right)$. Tribol. Lett. 2000, 8, 65-78. [CrossRef]

13. Woydt, M. Sub-stoichiometric Oxides for Wear Resistance. Wear 2019, 438, 203104. [CrossRef]

14. Hardell, J.; Hernandez, S.; Mozgovoy, S.; Pelcastre, L.; Courbon, C.; Prakash, B. Effect of oxide layers and near surface transformations on friction and wear during tool steel and boron steel interaction at high temperatures. Wear 2015, 330, 223-229. [CrossRef]

15. Wallace, F.J.; Wordsworth, R.A.; Dowson, D.; Lansdown, A.R.; Alexander, W.; Reiter, H. US Army Workshop on Low Heat Rejection Engines (4th); Leeds University: Leeds, UK, 1989.

16. Beadling, A.R.; Bryant, M.G.; Dowson, D.; Neville, A. A link between the tribology and corrosive degradation of metal-on-metal THRs. Wear 2017, 113, 354-361. [CrossRef]

17. Zhang, S.Y.; Feng, S.S. Friction and wear performances of brake material dry sliding against a composite with a semiinterpenetrating network structure of ceramics and Al-alloy. Tribol. Int. 2011, 44, 248-257. [CrossRef]

18. Hardell, J.; Prakash, B. High-temperature friction and wear behaviour of different tool steels during sliding against Al-SI-coated high-strength steel. Tribol. Int. 2008, 41, 663-671. [CrossRef]

19. Yao, S.H.; Kao, W.H.; Su, Y.L.; Liu, T.H. On the tribology and micro-drilling performance of TiN/AlN nanolayer coatings. Mater. Sci. Eng. A 2004, 386, 149-155. [CrossRef]

20. Woydt, M. Application oriented tribological test concepts. Lube Tech. 2017, 130, 22-28.

21. Obert, P.; Müller, T.; Füßer, H.J.; Bartel, D. The influence of oil supply and cylinder liner temperature on friction, wear and scuffing behavior of piston ring cylinder liner contacts-A new model test. Tribol. Int. 2016, 94, 306-314. [CrossRef]

22. Woydt, M.; Ebrecht, J. Testing friction and wear of the tribosystem piston ring and cylinder liner outside of engines. Lubr. Sci. 2008, 14, 113-126. [CrossRef]

23. Podgornik, B.; Vižintin, J. Tribology of thin films and their use in the field of machine elements. Vacuum 2002, 68, 39-47. [CrossRef]

24. Mano, H.; Ohana, T. Evaluation of anti-adhesion characteristics of diamond like carbon film using reciprocating ball-on-plate tribometer. Wear 2017, 386, 188-194. [CrossRef]

25. Schneider, A.; Steinmueller-Nethl, D.; Roy, M.; Franek, F. Enhanced tribological performances of nanocrystalline diamond film. Int. J. Refract. Met. Hard Mater. 2010, 28, 40-50. [CrossRef]

26. Thoma, M. High Wear Resistance at High Temperatures by a $\mathrm{Co}+\mathrm{Cr}_{2} \mathrm{Or}_{3}$ Electrodeposited Composite Coating. In Proceedings of the 4th International Tribology Symposium, Eurotrip 85: IV; Elsevier: Lyon, France, 1985. 
27. Kayaba, T.; Iwabuchi, A. The fretting wear of $0.45 \% \mathrm{C}$ steel and austenitic stainless steel from 20 to $650{ }^{\circ} \mathrm{C}$ in air. Wear 1981,74 , 229-245. [CrossRef]

28. Rybiak, R.; Fouvry, S.; Bonnet, B. Fretting wear of stainless steels under variable temperature conditions: Introduction of a 'composite' wear law. Wear 2010, 268, 413-423. [CrossRef]

29. Hurricks, P.L. The fretting wear of mild steel from room temperature to $200{ }^{\circ} \mathrm{C}$. Wear 1972, 19, 207-229. [CrossRef]

30. Hurricks, P.L. The mechanism of fretting-A review. Wear 1970, 15, 389-409. [CrossRef]

31. Taylor, D.E.; Hardisty, F.B.; Waterhouse, R.B.; Nehru, A.Y. The fretting wear of an austenitic stainless steel in air and in carbon dioxide at elevated temperatures. Wear 1979, 56, 9-18. [CrossRef]

32. Rustamov, I.; Wang, Y.; Wang, Z. Triple Heat Treatment Effects on the Microstructure and Fretting Wear Behavior of Inconel X-750 Alloy. In Proceedings of the 46th Leeds-Lyon Symposium on Tribology, Lyon, France, 2-4 September 2019.

33. Jacobs, C. Worries over Fretting Wear. Lubesngreases. Available online: https://www.lubesngreases.com/magazine/worriesover-fretting-wear/ (accessed on 1 October 2020).

34. Erdemir, A. Review of engineered tribological interfaces for improved boundary lubrication. Tribol. Int. 2005, 38, 249-256. [CrossRef]

35. Erdemir, A. Solid lubricants and self-lubricating films. In Modern Tribology Handbook; Bhushan, B., Ed.; CRC Press: Boca Raton, FL, USA, 2001; pp. 787-818.

36. Holmberg, K.; Ronkainen, H.; Matthews, A. Tribology of thin coatings. Ceram. Int. 2000, 26, 787-795. [CrossRef]

37. Hogmark, S.; Jacobson, S.; Larsson, M.; Wiklund, U. Mechanical and tribological requirements and evaluation of coating composites. In Modern Tribology Handbook; Bhushan, B., Ed.; CRC Press: Boca Raton, FL, USA, 2001; pp. 931-959.

38. Wang, H.D.; Zhuang, D.M.; Wang, K.L.; Liu, J.J. Comparison of the tribological properties of an ion sulfurized coating and a plasma sprayed FeS coating. Mater. Sci. Eng. A 2003, 357, 321-327.

39. Julthongpiput, D.; Ahn, H.S.; Sidorenko, A.; Kim, D.I.; Tsukruk, V.V. Towards self-lubricated nanocoatings. Tribol. Int. 2002, 35, 829-836. [CrossRef]

40. Erdemir, A.O.; Ajayi, O.O.; Fenske, G.R.; Erck, R.A.; Hsieh, J.H. Synergistic effects of solid and liquid lubrication on the tribological behavior of transformation-Toughened $\mathrm{ZrO}_{2}$ ceramics. Tribol. Trans. 1992, 35, 287-292. [CrossRef]

41. Erdemir, A.; Erck, R.A.; Fenske, G.R.; Hong, H. Solid/liquid lubrication of ceramics at elevated temperature. Wear 1996, 203, 588-594. [CrossRef]

42. Erdemir, A. Tribological properties of boric acid and boric-acid-forming surfaces: Part 1, crystal chemistry and mechanism of self-lubrication of boric acid. Lubr. Eng. 1991, 47, 168-172.

43. Erdemir, A.; Eryilmaz, O.L.; Fenske, G. Synthesis of diamondlike carbon films with superlow friction and wear properties. J. Vac. Sci. Technol. 2000, 18, 1987-1992. [CrossRef]

44. Gahlin, R.; Larsson, M.; Hedenqvist, P. ME-C: H coatings in motor vehicles. Wear 2001, 249, 302-309. [CrossRef]

45. Podgornik, B.; Jacobson, S.; Hogmark, S. Influence of EP and AW additives on the tribological behaviour of hard low friction coatings. Surf. Coat. Technol. 2003, 165, 168-175. [CrossRef]

46. Yasuda, Y.; Kano, M.; Mabuchi, Y.; Abou, S. Research on Diamond-like Carbon Coatings for Low-Friction Valve Lifters; SAE Paper No. 2001-03P-352; SAE International: Warrendale, PA, USA, 2003.

47. Veprek, S. New developments in superhard coatings: The superhard nanocrystalline-Amorphous composites. Thin Solid Film. 1998, 317, 449-454. [CrossRef]

48. Musil, J.; Vlcek, J. Magnetron sputtering of hard nano-composite coatings and their properties. Surf. Coat. Technol. 2001, 142, 557-566. [CrossRef]

49. Dumitru, G.; Romano, V.; Weber, H.P.; Pimenov, S.M.; Kononenko, T.M.; Hermann, J. Laser treatment of tribological DLC films. Diamond Relat. Mater. 2003, 12, 1034-1040. [CrossRef]

50. Dumitru, G.; Romano, V.; Weber, H.P.; Pimenov, S.; Kononenko, T.; Sentis, M. Femtosecond laser ablation of diamond-like carbon films. Appl. Surf. Sci. 2004, 222, 226-233. [CrossRef]

51. Morales, S.T. Method to Improve Solid Lubricant Film Tribological Performance and Adhesion to Hot Forming Material. Patent No. US8250890 B2, 28 August 2012.

52. Vergne, C.; Boher, C.; Gras, R.; Levaillant, C. Influence of oxides on friction in hot rolling: Experimental investigations and tribological modelling. Wear 2006, 260, 957-975. [CrossRef]

53. Felder, E. Modes of wear and damage of hot rolling rolls. Relationships with thermomechanical characteristics of calamines. Rev. Met. 1984, 12, 931-942. [CrossRef] 